\title{
Vorbemerkung:
}

Der nachstehende Artikel ist im vergangenen Jahr in der Zeitschrift „Arbeiterpolitik" erschienen. Der Redaktion ist aus Chile eine Kritik an diesem Artikel zugesagt worden, die in einer der nächsten Nummern der „Probleme des Klassenkampfes" erscheinen soll.

d. Red.

\section{CHILE ZWISCHEN BÜRGERLICHER LEGALITÄT UND SOZIALISTISCHER REVOLUTION}

In Chile stellt sich eine linke Regierung, die in Konsequenz eines Wahlsieges gebildet worden ist, die Aufgabe, die Grundlagen des Sozialismus aufzubauen und dabei die Regeln der Legalität zu respektieren. Die befremdende Lage verwirrt die Linken, denn es handelt sich nicht einfach um noch eine der zahlreichen bürgerlich reformistischen Versuche, sondern um eine Regierung, die von den gewerkschaftlichen und politischen Organisationen des chilenischen Proletariats am Ruder gehalten wird.

Es ist klar, daß die unverbesserliche reformistische Linke schon alle Illusionen über den „friedlichen Weg zum Sozialismus“ wiederbelebt hat. Innerhalb der revolutionären Linken, aber - und für diese interessieren wir uns näher, da nur sie schließlich den effektiven Kampf um den Sozialismus aufnehmen kann - ist die Verwirrung nicht kleiner. Das kann man schon bei den Meditationen eines Debray feststellen, der, nachdem er sich zum Theoretiker der Zurückführung des Klassenkampfes auf rein militärische Aspekte gemacht hat, jetzt zum naiven Verherrlicher Salvador Allendes und des Gleichgewichts zwischen Reform und Revolution wird. Debray handelt nicht anders als viele andere Gleichgesinnter, die überraschend von dem Wahlsieg der Unidad Popular - „Volkseinheit“ - und der Bedeutung der Massenbewegung, ihre ultralinke Haltung aufgeben, um sich dem „legalen Weg“ zu beugen. Sie konnten nicht anders, denn es fehlte ihnen die Klassenperspektive des Proletariats und ihr Radikalismus war nicht viel mehr als ein radikaler und kleinbürgerlicher Nationalismus. Andererseits haben wir auch die Sektoren der revolutionären Linken, die den Fortschritt des revolutionären Prozesses in 
Chile deshalb ignorierte, weil es sich nicht in ihre vorfabrizierten Schemen des „Volkskrieges" einreihen ließ. Ein Beispiel dessen ist die "Partido Comunista Revolucionario (PCR) - „Revolutionäre Kommunistische Partei“ - die lokale marxistische Gruppe. Vor den Wahlen hatte PCR behauptet, daß alle Kandidaten „pro-Imperialisten“ wären und hatte die Losung „Keine Wahlen, wir wollen den Kampf", als ob die "Wahl unter den gegebenen Umständen nicht auch ein Aspekt, wenn auch zweitrangiger, des Klassenkampfes dargestellt hätte. Es handelt sich wohl um eine legale Konfrontation aber gleichzeitig um eine Klassenkonfrontation und die Zusammensetzung der "Volkseinheit", ist vorwiegend proletarisch; sie besteht aus der Sozialistischen Partei, der Kommunistischen Partei, einer kleineren Splittergruppe des MAPU, linkskatholisch, und der Radikalen Partei kleinbürgerlichen Ursprungs.

\section{Erklärung der Abkürzungen:}

DR - Democracia Radical (Rechtspartei, antikommunistisch)

PN - Partido Nacional (Die beiden Parteien bilden die Rechtsopposition im Parlament)

DC - Democracia Christiana (Christ-Demokraten)

UP - Unidad Popular, „Volkseinheit"

MIR - Movimiento de la Izquierda Revolucionaria (Bewegung der Revolutionären Linken)

pobladores - Bewohner der Elendsviertel "slums"

Pobladores sin casa - Obdachlose

El Mercurio - konservative Tageszeitung

PS - Partido Socialista

PC - Partido Comunista

MCR - Movimiento Campesino Revolucionario (Rev. Bauernbewegung)

mapuches - chilenische Indianer, deren Ländereien in der Vergangenheit von den Weißen enteignet wurden

inquilinos - Pächter ohne juristische Garantien und die einen Teil ihrer Ernte (meistens die Hälfte) den Großgrundbesitzern abgeben müssen.

afuerinos - Landarbeiter, die nicht auf der Hacienda wohnen

MAPU - Ältere Abspaltung der Christ-Demokraten, die der „Volkseinheit" angehören. OLAS - Organizacion Latinoamericana de Solidaridad. Lateinamerikanische Organisation, die 1967 in Havanna gegründet worden ist (debrayistisch)

VOP - Vanguardia de Organizacion Popular. Organisierte Vorhut des Volkes.

„Momios" sind "Mumien". So werden im Volke die alten Konservativen DR und PN) genannt.

Die Allianz entspricht zur Zeit dem Niveau des Bewußtseins ger chilenischen Arbeiterklasse, das wohl antikapitalistisch ist, sich aber noch in legalistischen Vorstellungen bewegt. Nach den Wahlen war dieser Teil der revolutionären Linken infolge seiner Unfähigkeit, seine Haltung kritisch durchzudenken, und die Eigenheiten des revolutionären Prozesses in Chile zu verstehen, zur vollständigen Isolation verurteilt und begnügte sich damit, weltfremde Losungen von sich zu geben, die keinerlei Widerhall haben können.

Es ist klar, daß die Besonderheiten einer Lage, wie der gegenwärtigen in Chile, die Ausarbeitung einer richtigen Linie erschweren und nur ein billiger 
Betrüger könnte behaupten, ein vollständiges und unfehlbares Rezept zu besitzen. Aber es ist heute die Pflicht eines jeden Revolutionärs, die Haltung der chilenischen Linken zu untersuchen und dazu beizutragen, daß sie ihren Aufgaben gerecht werden.

\section{Einige Daten über die wirtschaftliche Struktur Chiles}

Seit den Dreißigerjahren stellt die Industriemanufaktur ${ }^{2}$ ) den dynamischen Sektor des chilenischen Kapitalismus dar. Die Industrie wuchs indessen innerhalb des Rahmens, den die alte Struktur, mit einer Vorherrschaft der Mineralexporte und einer von einem tiefen Produktionsniveau gekennzeichneten Landwirtschaft, geschaffen hatte. Unter diesen Umständen schuí die kapitalistische Akkumulation einen schnell zunehmenden Prozeß der monopolistischen Konzentration, begleitet von imperialistischer Vorherrschaft und einer wachsenden Beteiligung des Staates.

Folgende Statistiken zeigen die vorherrschende Rolle der Manufakturindustrie und gleichzeitig das wachsende Gewicht des Tertiärsektors in der chilenischen Wirtschaft

\section{Prozentuelle Verteilung des Sozialprodukts (1968)}

$\begin{array}{lr}\text { Landwirtsch. Forstwesen } & \\ \text { Jagd und Fisch } & 10,0 \% \\ \text { Hüttenwesen } & 9,7 \% \\ \text { Industrie Manufakt. } & 25,7 \% \\ \text { Bauwesen } & 4,5 \% \\ \text { Elektr. Gas Wasser } & 1,7 \% \\ \text { Verkehrsw. Lagerw. } & 4,4 \% \\ \text { Handel } & 21,6 \% \\ \text { Andere Dienstl. } & 21,9 \%\end{array}$

Innerhalb der Industrie sind es die traditionellen Zweige, die vorherrschen. Der Reihenfolge nach sind es: (Prozente des Industrieprod.) Nahrungsmittel $(11,8 \%)$, Schuhe und Kleider $(10,8 \%)$, Textilien $(10,8 \%)$. Danach folgen moderne Zweige der Produktionsmittelindustrie und verarbeitende Industrien: Transportmittelproduktion $(6,8 \%)$ und Metallurgie $(6,4 \%)$. Bedeutsam ist jedoch, daß die Wachstumsrate für den Zeitabschnitt 1960-67 am größten für die Produktionsmittelindustrie ist $(13,4 \%)$, danach kommt die verarbeitende Industrie $(6,6 \%)$ und zuletzt die Gebrauchsgüterindustrie $(3,3 \%)$. Das Wachstum der. Rolle der Schwerindustrie hat Mitte der fünfziger Jahre begonnen und wurde von einer sich ständig intensivierenden Verquickung mit dem imperialistischen Auslandskapital von einer monopolistischen Konzentration 
und einer Verminderung der Wachstumsrate des variablen Kapitals begletet. Diese neue Phase wurde gekennzeichnet durch eine Verbindung der Politik der „Import-Substitution“ (Ersatz der Importe durch eigene Erzeugnisse) mit der semi-populistischen Politik der Christ-demokraten, welche die kapitalistische Entwicklung in eine Sackgasse führte und die schnell wachsende Inflation der letzten Jahre der Sechzigerdekade mit sich brachte.

1963 haben bereits 3\% der Großbetriebe (mit mehr als 200 Lohnempfängern) $58 \%$ des Industriekapitals in ihren Händen konzentriert und $44 \%$ der industriellen Arbeitskraft beschäftigt. Die mittleren Betriebe (zwischen 20 und 200 Lohnempfängern) verfügten über $35 \%$ des Kapitals und $40 \%$ der Arbeitskraft und stellten $30 \%$ der Produktionsstätten dar. Die Kleinindustrie (mit 5 bis 20 Lohnempfängern) stellte $67 \%$ der Betriebe dar, verfügte über $7 \%$ des Kapitals und 16\% der Arbeitskraft.

Die Großbourgeoisie, die diesem Industrialisierungsprozeß entsprang, zeichnet sich durch den hohen Grad der Konzentration und der Abhängigkeit vom Imperialismus aus. Das Proletariat, andererseits, welches bereits eine entscheidende Rolle in der chilenischen Gesellschaft spielt, zeichnet sich duch ein langsames aber stetes Wachstum, aber auch durch den hohen Konzentraditionsgrid im Hüttenwesen und der Großindustrie auš. 20\% der im Lande vorhandenen Arbeitskraft wird von der Industriemanufaktur absorbiert (= 580000 Lohnempfänger, = 1967). Ungefähr 353000 sind Fabrikarbeiter. Wenn wir Minen-, Bau- und Transportarbeiter und die der öffentlichen Dienste dazuzählen, ergibt sich eine Gesamtzahl von ungefähr 600000 Arbeitern. Die Volkszählung von 1960 gibt als Prozentsatz der aktiv tätigen Bevölkerung 44,9 als "Arbeiter" an, aber darunter befinden sich 63\% Landarbeiter und Kleinbauern, die teilweise Lohnarbeit verrichten und $12 \%$ Handelsangestellte. Auf jeden Fall sieht man die Vorherrschaft typisch kapitalistischer Ausbeutungsverhältnişse. (Daten aus „La Economia Chilena“).

Bedeutend ist das Ausmaß der Arbeitslosigkeit und der Unterbeschäftigung. 1967 waren 137000 Arbeitslose öffentlich angemeldet und das stellt 4,8\% der gesamten Arbeitskraft dar. Es ist sicher, daß diese Zahlen nicht vollständig sind und sie erfassen auch nicht die Unterbeschäftigten. Es genügt zu wissen, daß $196054,5 \%$ der in Handel und Dienstleistung tätigen (die 30\% der Arbeitskraft ausmachen) als "Selbständig" registriert waren. Vor kurzem hat der Präsident der Gewerkschaftszentrale die Anzahl der Érwerbslosen mit 400000 angegeben.

Der staatliche Sektor des chilenischen Kapitalismus wuchs außerordentlich schnell und das einerseits, um den bremsenden Wirkungen der Monopolstruktur entgegenzuwirken und andererseits, um den schwachen akkumulationsprozeß im privaten Sektor zu ergänzen. Zwischen 1961 und 66 sind ungefähr $31 \%$ aller Investitionen vom Staate gemacht worden. Das damit verbundene Wachstum der öffentlichen Dienste hat seinerseits eine Auswirkung im Sektor des Konsums mit sich gebracht, wobei Bürokraten und besserge- 
stellte Angestellte die Konsumenten waren, was zum relativen Industriewachstum beigetragen hat, das sich bis 1966 hielt. 1962 arbeiteten für den Staat 275000 Lohnempfänger (ungefähr 10\% der Arbeitskraft des Landes), von denen 30\% Arbeiter waren. Die große Abhängigkeit der chilenischen Industrie vom Staate hat der Bürokratie eine beträchtliche Macht verliehen und auf die Art zur Stabilität der bestehenden politischen Institutionen beigetragen.

Lange Zeit hindurch war die chilenische Volkswirtschaft dadurch gekennzeichnet, daß die im Minensektor (der für die Ausfuhr produzierte) stattfindende Akkumulation keinen nennenswerten Effekt auf das wirtschaftliche Leben des Restes des Landes ausübte: vom ausländischen Kapital beherrscht, stellt er einen zum Großteil autonomen Sektor dar, der sich auch nach dem Ausland ausrichtet. Mit der Verschiebung der dynamischen Kräfte der Wirtschaft zum Manufaktur-Sektor ist dieser in die Lage gekommen, den Staat zu benutzen, um dem für die Ausfuhr produzierenden Sektor wachsende Anteile abzugewinnen, um auf diese Art die schwächliche innere Akkumulation zu finanzieren. Infolge ihrer Anhängigkeit vom Ausland hat es die chilenische Bourgeoisie vorgezogen, die Minen in den Händen des Auslandkapitals zu belassen und sich einen Anteil mittels einer flexiblen Steuer olitik zu sichern. Heute hat dieser Sektor eine viel kleinere Bedeutung als zu Beginn des Jahrhunderts, aber das Minen proletariat hebt sich immer noch durch seine Anzahl, seine Konzentration und seine Kampftradition hervor. Die Landwirtschaft beschäftigt $24,4 \%$ der vorhandenen Arbeitskraft, obwohl sie nur $9 \%$ des Sozialproduktes hervorbringt. Man kann nicht behaupten, daß die landwirtschaftlichen Reichtümer erschöpft sind. Das Gegenteil ist der Fall, aber was bestimmend ist, ist eine ungenügende Aufnahmefähigkeit des Landwirtschaftsprodukies durch den Markt. Von 4,2 Millionen Hektar fruchtbaren Landes sind bloB 1,5 Millionen Hektar 1965 bebaut worden. Andererseits ist Chile gezwungen, ungefähr für 200 Millionen Doliar jährlich Nahrungsmitiel und Rohprodukte zu importieren, was annähernd $15 \%$ des Wertes seiner Ausfuhren ausmacht.

Von 481000 Personen, die 1966 die wirtschaftlich aktive Bevölkerung der Landwirtschaft ausmachten, waren 333000 Landarbeiter, 11000 Angestellte und 137 Eigentümer. Das Verteilungsbild des ländlichen Einkommens läßt auch den hohen Grad der Unzufriedenheit der Landbevölkerung verstehen:

Durchschn. Einkomm Ländl. Bevölk. \% Einkommen in \% in Escudos

und Kleinbauern

(inklusive Pächter) $\quad 70,0$

Familieneigentümer 17,7

Angestellte

2,1

Mittleres Eigentum

Großeigentum
6,5

3,0
33,4

12,7

1,8

15,4

36,7
63,6

96,6

1178,0

3202,0

$\$ 6582,0$ 
Die Tatsache, daß sich bereits klar kapitalistische Verhältnisse im Produktionsverhältnis herauskristallisiert haben, findet seinen Niederschlag in den sozialen und wirtschaftlichen Zuständen auf dem Land, im großen Unterschied zwischen Landarbeitern und Kleinbauern einerseits und der entstandenen Mittelklasse und dem Großbesitz andererseits. Dazu kommt noch die Schaffung einer Mittelschicht relativ privilegierter Angestellter.

Von A. G. Frank zitierte Daten vervollständigen das Bild in Hinsicht auf die Stadtbevölkerung. Der Vergleich wird hier zwischen Industriekapitalisten, Angestellten, Industriearbeitern und Landarbeitern gezogen:

\begin{tabular}{lcc} 
& Bevölkerung $(\%)$ & Einkommen $\ell \%)$ \\
\cline { 2 - 3 } Industriekapitalisten & 4,7 & 39,3 \\
Angestellte & 18,6 & 37,7 \\
Arbeiter & 47,7 & 18,9 \\
Landarbeiter & 29,0 & $4,1$.
\end{tabular}

1964 hatte sich der politische Kampf in Chile zwischen den.Kandidaturen Frei und Allende polarisiert. Chile stellte einen seltenen Fall in Südamerika dar, in dem der Klassenkampf ein bürgerlich demokratisches System hervorgebracht hat, in welchem Wahlen tatsächlich zu einem entscheidenden Moment der Änderungen innerhalb der Struktur geworden sind. (Die bürgerlich-demokratische Stabilität bedeutet noch nicht das Fehlen von Gewaltakten. Im Gegenteil, die Massaker chilenischer Arbeiter durch die Unterdrückungsorgane finden wenig Parallelen auf dem Kontinent, was Brutalität und Anzahl der Opfer betrifft). In den Wahlen von 1964 haben beide Kandidaten „tiefgehende Reformen" versprochen. Allende war Kandidat der Linkskoalition, welche sich um KP und SP gebildet hatte und von der mächtigen Central Unica de los Trabajadores, der Gewerkschaftszentrale, unterstützt wurde. Trotz der Mäßigung seines Reformprogrammes - die klassische Plattform der Mehrheit der Kommunistischen Parteien des Kontinents: Nationalisierungen, Agrarreform usw., welche das bürgerliche Regime nicht in Frage stellt hat die marxistische und proletarische Färbung seiner gesellschaftlichen Stützen unter der Bourgeoisie Panik ausgelöst. (Um eine Idee vom proletarischen Charakter der Stimmen, die Allende gegeben worden sind, zu haben, genügt die Tatsache, daß er in allen städtischen Distrikten, mit mehr als $40 \%$ Arbeitereinwohnern, $40 \%$ und mehr der abgegebenen männlichen Stimmen auf sich vereinigen konnte. - Untersuchung von Zeitlin und Petras). Aber selbst Frei, der von der Rechten unterstützt wurde, predigte die „Revolution in Freiheit" und die Ersetzung der kapitalistischen Ordnung durch eine "Orden communitaria". Er war in der Praxis Sprachrohr des "Kennedismus" und der „Allianz für den Fortschritt“. Er stützte sich auf den dynamischen Sektor des Kapitalismus, der ein Interesse an einer Modernisierung der Landwirtschaft herausbildete und der sich in entstellter Form in den reformistischen 
größere Bevölkerungsteile in die bürgerliche Demokratie zu integrieren, um die soziale Revolution zu vermeiden.

In Summa: Keiner der beiden Pole, die sich in den Wahlen 1964 gebildet hatten, verteidigte offen das bestehende Regime. Warum? Und welches war der reale revolutionäre Prozeß, der sich langsam in der chilenischen Gesellschaft herausbildete und der sich in enstellter Form in den reformistischen Programmen widerspiegelte?

Von 1958 bis 1964 war Jorge Alesandri Präsident geworden. Es handelt sich um die repräsentativste Figur des Konservatismus, dessen reaktionärer Charakter in Volkskreisen durch das Image des ehrlichen Patriarchen kompensiert wurde. Unter dieser Regierung kamen alle Widersprüche der kapitalistischen Industrialisierung klar an das Tageslicht und seine Politik ließ keine Zweifel mehr über den Platz, der den Massen der Werktätigen innerhalb der bürgerlichen Entwicklungspolitik zugewiesen ist. Während seiner Regierungszeit hat sich die Industrialisierung verschnellert, neue Produktionszweige wurden eröffnet. Die städtische Mittelklasse wuchs infolge der Expansion der Dienstleistungen und der Urbanisation. Auch der Exportsektor wuchs, was wiederum eine Vergrößerung der Einfuhren gestattete (von 350 Millionen Dollar Mitte der 50-Jahre auf 800 Millionen zu Ende der 60-Dekade). Trotzdem bestand seine Wirtschaftspolitik in einem offenen und rigorosen Lohnstop und finanziellen Sparprogramm. Inmitten des größten wirtschaftlichen Wachstums haben die Arbeiter unter den schlimmsten Verhältnissen kapitalistischer Ausbeutung gelitten.

Die beschleunigte Industrialisierung hat Chile nicht weniger abhängig gemacht. Die Direktinvestitionen der Vereinigten Staaten sind im traditionellen Minensektor praktisch gleich geblieben: Die Summe von 517 Millionen Dollar im Jahre 1960 hat bis 1967 keine Änderungen erfahren und ist erst 1968 auf 586 Millionen gestiegen. Von da an ist es sicher, daß sie gefallen ist, infolge der Nationalisierungsprozesse, die stattfanden oder angekündigt worden sind. In der Manufaktur sind sie jedoch gewachsen: von 22 Millionen Dollar im Jahre 1960 auf 68 Millionen 1968. Im Handel kletterten sie in der selben Zeitspanne von 12 Millionen auf 39. Gleichzeitig wuchs die Auslandsverschuldung von 7 Millionen 1962, auf 10,7. Millionen 1965, und 16 Millionen 1968.

Die Industrialisierung hat die Früchte des wirtschaftlichen Wachstums nicht den Volksmassen zugute kommen lassen, die verelendeten Massen wurden nicht „integriert“ und das Gefälle der Einkommen wurde nicht verringert. Im Gegenteil, zwischen 1960 und 1965, als der Industriesektor jährlich im Durchschnitt 6,5\% wuchs, ist der Anteil der Löhne und Gehälter am Bruttowert des Sozialproduktes von 33,7\% auf 30\% gefallen. Zwischen 1950 und 1968 ist die Summe der Löhne. und Gehälter von 46,7\% auf $36,5 \%$, als Anteil der Industrieeinkommen, gefallen. Das ist die Lösung, die der unterentwickelte Kapitalismus gefunden hat, um sich der Beschränktheit des inneren Marktes und der defizienten Akkumulation anzupassen. Es ist der Weg der frühen 
Konzentration, der Unterordnung unter den Imperialismus, der Monopolbildung und der Ersezzung von Arbeitskraft durch die Maschine .Das Resultat ist das ungeheure Wachsen des Einkommengefälles und die ständige Existenzbedrohung der nicht gebrauchten Arbeitskraft.

Die Regierung Frei versprach, die Krise zu lösen. In den Wahlen von 1963 ist bereits eine Million Stimmen den Kandidaten der kommunistisch-sozialistischen Koalition gegeben worden, und auf dem ganzen Kontinent war die Begeisterung der Massen über das kubanische Beispiel im Wachsen, das begleitet war von einer fortschreitenden Müdigkeit aller bürgerlichen Entwicklungsversuche, die zugleich die jahrhundertalte Ausbeutung und Unterdrückung weiterführten. Diese Herausforderung der bestehenden Ordnung wurde von den systemerhaltenden Kräften mit den Reformen a Ia „Allianz für den Fortschritt" beantwortet. Die Christ-Demokratie setzte sich zum Ziel, den inneren Markt zu vergrößern, mittels einer Agrarreform (in der das Land den Bauern individuell oder mittels Kooperativen zur Verfügung gestellt werden sollte); die Beteiligung der Massen am institutionellen Leben zu intensivieren, (besonders der Landbevölkerung, die ziemlich unorganisiert war, und die man als Gegengewicht zu den von der Linkskoalition beherrschten Arbeitsorganisationen benutzen wollte); und schließlich die industrielle Entwicklung vorwärtstreiben, indem man den dynamischsten Sektor unterstützte. Das wirtschaftliche Wachstum setzte sich 65 und 66 fort, 1967 jedoch erlitt zu es plötzlich Rückschläge, die sich zu einer Krise entwickelten. Damit wurden die Massen, die von Frei mobilisiert worden waren und die scheinbar zu einer Barriere für die Weiterausbreitung der Linken gewesen sind, zu einer neuen Gefahr für das Regime, denn sie forderten die Einlösung der Wahlversprechen. Die Schichten, die 1964 im Namen der "Revolution in Freiheit" von Allende gewonnen waren, sind der Illusion des „3. Weges“ zum Opfer gefallen, aber sie haben tatsächlich an die versprochenen radikalen Änderungen geglaubt. Die christdemokratischen Mythen, in dem Maße, wie sie in die Massen drangen, haben sich auch in eine materielle Kraft verwandelt und ihre Führer, die im Einverständnis mit der lokalen Plutokratie handelten, konnten die politische Kraft, die sie geschaffen hatten, um die sozialistische Welle zu brechen, nicht mehr straflos ignorieren. Jetzt begann innerhalb der ChristDemokratie ein'Differenzierungsprozeß zwischen der Führung, die die „modernisierende" Großbougeoisie vertrat, und einen linken Flügel, der dem Druck der unzufriedenen Anhänger ausgesetzt war. Der christ-demokratische Reformismus, pro-imperialistisch wie er war, hat sich unfähig gezeigt, die Lage im Lande zu stabilisieren und die Konsequenz war, daß er immer mehr zu repressiven Mitteln griff.

Die Politik der industriellen Entwicklung, die sich auf die Befriedigung der Kaufkraft der Schichten mittleren und höheren Einkommens gründete, kam in Widerspruch zu den Notwendigkeiten einer Produktion für breitere Volksmassen, wie auch zu den Plänen zur Herstellung einer Infrastruktur, die die 
Kontinuität des Entwicklungsprozesses ermöglichen sollte. Obwohl der Sektor des Außenhandels noch gute Positionen innehatte, zeigt das schnelle Anwachsen der Inflation ab 1969 die Engpässe dieses Typs der Entwicklung auf. In der Landwirtschaft wollte die christ-demokratische Regierung die Laßifundios, den Großgrundbesitz, zwingen, sich zu modernisieren - unter Androhung von Enteignungen - um auf diese Weise auch eine ländliche Mittelklasse zu schaffen. Bis März 1970 wurden Ländereien von insgesamt 3 Millionen Hektar enteignet. Die Gesamtausdehnung der Latifundien ist 30,6 Millionen Hektar. Die Enteignungen waren nicht groß genug um das Latifundiensystem zu vernichten, aber genügend $u m$ es zu einer Modernisierung zu zwingen und die Last, die es für die Volkswirtschaft darstellt, zu verringern.

Andererseits lebten Ende 196917400 Familien auf enteigneten Ländereien. Laut Gesetz sollen die Bauern, nach drei Jahren Regierungsverwaltung und „Versuchen“ einer bäuerlichen Mitbestimmung unter staatlichen Vormund, selber bestimmen, ob sie die Erde individuell oder kollektiv bearbeiten wollen. Wie man sieht, war die Anzahl der Bauern, die aus der Reform Nutzen ziehen konnten, außerordentlich klein, aber der Widerhall war viel größer, da die Maßnahmen innerhalb der ländlichen Bevölkerung große Erwartungen hervorriefen.

Das allgemeine Resultat der christdemokratischen Experimente bestand darin, daß sie, unfähig den Fortschritt eines revolutionären Prozesses aufzuhalten, inm noch den Weg bahnten, indem sie neue Hoffnungen der Massen erweckten, ohne sie erfüllen zu können.

Die Wahlen von 1970 spielen sich in einem noch mehr radikalisierten Lande ab. Die Wirtschaftskrise hat alle Widersprüche des Regimes an die Oberfläche gebracht. Es hat sich eine ,Revolutionäre Linke' gebildet, die vom Movimiento da Izquierda Revolucionaria (MIR) geführt, eine reale Drohung des bewaffneten Kampfes gegen das Regime darstellt. Die schließliche Abspaltung eines linken Flügels von der Christ-Demokratie wiederspiegelt die Enttäuschungen der Schichten, die die Partei in der Hoffnung ęiner "Revolution" unterstützt hatten, die nicht gekommen ist. Die wachsende Mobilisation der Bauern und ihre Autonomiebestrebungen - 2 der 3 Bauernföderationen hatten sich bereits mit den Linken verbunden - drängte auf die schnelle Realisierung der Agrarreform. In den Vororten der Städte häuften sich die gewaltsamen Besetzungen von Wohnstätten durch "pobladores", die Zuwanderer, die am Rande der Städte leben, ohne Arbeit und Behausung zu finden. (Sie wurden meistens vom MIR organisiert.) Und schließlich wuchs der Kampf und die Organisation der Arbeiterklasse.

Angesichts dieses Anwachsens der Massenbewegung der Linksorganisationen teilt sich die chilenische Bourgeoisie. Die extreme Rechte versucht es noch einmal mit dem alten Alessandri, mit einem Programm der Sparmaßnahmen und der Vorbeugung, der revolutionären Gefahr offen entgegenzutreten. Der Rechtskandidat wollte mit dem christ-demokratischen "Abenteuer" aufräumen, welches "der Subversion die Türen geöffnet hat". 
Die Christ-Demokraten gehen weiter den Weg der sozialen Reformen, der die revolutionäre Welle auslaufen lassen soll. Dieses Mal, infolge der offensicht!ichen Radikalisierung ihrer Wählerschaft, ist ihr Programm noch "linker" als es 1964 war. Tomic, ihr Kandidat, vertritt innerhalb der Christ-Demokratie den "linken" Flügel, in Opposition der Rechten um Frei. (Eine radikalere Richtung hatte sich allerdings schon vorher abgespalten.)

Die Linkskoalition schließlich, die kommunistische und die sozialistische Partei, die jetzt von der christ-demokratischen Abspaltung und der kleinbürgerlichen Radikalen Partei verstärkt wurde, stellte noch einmal die Kandidatur Allende auf. Aber auch die Linke ist von der fortschreitenden Radikalisierung der breiten Massen nicht unberührt geblieben.

\section{Kräfteverhältnis und „Weg der Legalität"}

Das Endresultat der Wahlen ergab 1.075.616 Stimmen für Allende $(36,3 \%)$, 1.036 .278 für Allessandri $(34,98 \%)$ und 824.849 für Tomic $(27,84 \%)$. Keiner der Kandidaten hatte die absulute Mehrheit erreicht, und die Entscheidung zwischen Allende und Allessandri lag beim Kongreß. Die langjährige politische Tradition Chiles trug dazu bei, daß der Kongreß den Sieg Allendes bestätigte.

Es ist klar, daß eine politische Tradition noch kein unübersteigbares Hindernis bildet, um die legale Machtübernahme eines sozialistischen Kandidaten zu vereiteln. Die Funktion der Traditionen besteht gerade darin, die Stabilität der Institutionen zu garantieren: Und wenn die Kontinuität einer Tradition eine größere Gefahr für die Stabilität darstellt, als ihre Verletzung, so zeigen die ständigen Militärputsche Lateinamerikas, was die beste Lösung für die herrschende Klasse darstellt.

Tatsache ist aber auch, daß die herrschenden Klassen nicht immer so regieren können, wie sie möchten. Denn die beherrschten Klassen besitzen ein spezifisches Gewicht in der Bestimmung des Ablaufs der Ereignisse, und auch die politischen und ideologischen Kräfte, die die herrschenden Klassen im Laufe des Kampfes beschwören, haben gleichfalls ihre eigene Dynamik und können nicht nach Wunsch und Laune einfach annuliert werden. Die liberale Rechtsideologie, der Mythos der Volksouveränität durch den Stimmzettel, die "Neutralität des Heeres“, die Christ-Demokratie, welche die „,humanistische Revolution" als Alternative zur "totalitären" sozialistischen stelltalle diese Waffen des bürgerlichen Arsenals müßten erst überwunden werden, damit eine simple militärische Lösung Aussicht auf Erfolg haben kann. Die Tatsachen zeigten, daß dafür vor der legalen Einsetzung des siegreichen Kandidaten die Zeit zu kurz war.

Der Kampf spielte sich auf dem Boden des legalen Vorgangs der Anerkennug durch den Kongreß $a b$. Aber es ist offensichtlich, daß hinter den formel- 
Ien Argumenten der Juristen und Parlamentarier das. reale Kräfteverhältnis im Lande ausschlaggebend war. Und dieses war einer bürgerlichen Lösung durch simple Gewaltanwendung nicht günstig. Die Bourgeoise konnte über die Stimmen, die Tomic gegeben worden sind, keine Illusionen haben. Der christ-demokratische Kandidat mußte, um einen Teil der radikalisierten Wählerschaft um sich vereinigen zu können, fast alle anti-imperialistischen und anti-monopolistischen Forderungen des Programms von Allende übernehmen. Obwohl diese in die undefinierten Formulierungen der christ-demokratischen Ideologie übersetzt worden waren, erklärt das Programm Tomic's, ein Instrument des „revolutionären Einsatzes im Kampfe gegen die kapitalistischen und neo-kapitalistischen Strukturen, gegen die imperialistischen Interessen der wirtschaftlichen Ausbeutung und politischen Unterordnung", usw., zu sein. Die soziale kleinbürgerliche Basis der Christ-Demokraten hätte offene Machenschaften seiner Vertreter mit den kompromittierten uitra-rechten „Mumien“ so leicht nicht geschluckt. Die Radikalisierung der Linkskräfte und die Stärkung der MIR stellten ein anderes Problem dar: Sicherlich würde ein Militärputsch in einem Lande mit der stärksten linken Massenbasis auf dem Kontinent - nach Kuba - einen revolutionären bewaffneten Kampf auslösen. Und schließlich mußte die Rechte noch ihre Putschpläne organisieren und die legalistischen Mythen erkämpfen, welche sie selbst jahrelang innerhalb der Streitkräfte genährt hatte.

Die äußerste Rechte, die von der Partido Nacional und der Democracia Radical verkörpert wird, versuchte unter allen Umständen die Übergabe der politischen Macht an Allende zu verhindern. Zu diesem Zweck hat sie die Finanzpanik der Bourgeoisie angeregt, d. h. Kapitalexport nach dem Ausland und Stop der inneren Investitionen in Industrie und Lan.dwirtschaft. Allein in den Monaten September und Oktober 1970 sind 31 Millionen Dollar nach dem Ausland geflossen, was ungefähr $2,5 \%$ des gesamten Jahresexportes des Landes darstellt. Die nordamerikanischen Unternehmen entwickelten eine unverhohlen provokatorische Haltung und drohten ihre Aktivitäten einzustellen und ihre Angestellten nicht zu bezahlen. Auf dem Lande war es dasselbe. Andererseits begann die Rechte die Fäden der militärischen Konspiration zu ziehen, ohne deshalb auf die legale Lösung, der Nichtanerkennung durch den Kongreß, zu verzichten. Da diese Lösung, um die notwendige Mehrheit im Kongre $B$ zustandezubringen, von einer Mitarbeit der Christ-Demokraten abhing, erklärte Alessandri, daß er, falls von den Parlamentariern zum Präsidenten gewählt, zurücktreten würde, um eine neue Wahl zu ermöglichen.

Und um keine Zweifel zu lassen, erklärten Partido Nacional und Democracia Nacional öffentlich, daß sie die Kandidatur Freis unterstützen werden, falls dieser sie annehmen sollte.

Eduardo Frei war von der vorgeschlagenen Lösung mehr als eingenommen, aber die inneren Gegensätze der Christ-Demokratie erlaubten sie nicht. Tomic hatte am Tage nach der Veröffentlichung des Wahlergebnisses Allende 
in seiner Wohnung aufgesucht, um seine Anerkennung des Sieges der Unidad Popular auszudrücken. Er drückte somit die Ablehnung seiner Wählerschaft gegen jegliche Verbindung der Christ-Demokraten mit den rechten Putschisten aus und gleichzeitig auch die Furcht, daß eine solche Lösung das Land vor die unmittelbare Alternative Militärdiktatur oder Arbeiterrevolution stellen würde.

Die Christ-Demokratie, die zwischen Treue zum bürgerlichen Regime und zu seiner reformistischen Anhängerschaft hin und her schwankte, rieb sich an seinen inneren Gegensätzen auf, aber auch die Unidad Popular hatte ihre Probleme zu bewältigen und litt an einer fehlenden Entscheidungskraft. Unmittelbar nach der Veröffentlichung der Wahlergebnisse überflutete eine noch nie dagewesene Menschenmasse das Zentrum von Santiago. Aus den entferntesten Vororten und Arbeiterbezirken kommend fand sie sich zu einem Volksfest zusammen, das der Rechten die Stärke und Entschlossenheit der Linkskräfte deutlich vorexerzierte. Innerhalb der UP war für die Einen dieser Faktor die größte Garantie gegen einen Militärputsch. Aber die Meinungen waren geteilt: Andere bauten mehr auf einen Kompromiß mit den ĊhristDerhokraten und eine Befriedungspolitik mit Hilfe der Streitkräfte. Als bei rechten Putschdrohungen das Heer alle öffentlichen Versammlungen verbot, war es klar, daß es damit die Basisgruppen der UP unterlaufen wollte und sich als einziger Garant der öffentlichen Ordnung vorstellte. Die UP hat nicht falsch gehandelt, als sie die Christ-Demokratie zwang, öffentliche legalistische Verpflichtungen abzugeben, aber es war bedenklich, sich damit zu begnügen und das Wichtigste beiseite zu lassen: die politische Mobilisation der Werktätigen.

Nach langen inneren Kämpfen, beschloß die Christ-Demokratie, den Sieg Allendes anzuerkennen, unter der Bedingung, daß die UP im Kongre $B$ ein "Garantiestatut" unterzeichne, in welchem die neue Regierung sich verpflichte "das demokratische Regime zu respektieren“. Die listigen Führer der Democracia Christiana wollten sich auf diese Weise die Rolle der „Hüter der Demokratie" sichern. Indem sie den Machtantritt des gewählten Kandidaten garantierten (und damit ihre kleinbürgerliche Wählerschaft befriedigten), dachten sie zur gleichen Zeit, dem Sieger Verpflichtungen abzuhandeln, die später abverlangt werden könnten und wenn es sein muß, durch die Streitkräfte. Auf diese Art gedachten sie sich auch der chilenischen Bougeoisie als die geeigneten Politiker zu empfehlen, die eine "Katastrophe" verhüten können. Das delikateste Problem der Ausarbeitung des Garantiestatus bestand darin, daß es nicht ausdrücklich auf der Erhaltung des kapitalistischen Regimes bestehen konnte, denn das hätte die christ-demokratischen Füchse vor großen Teilen ihrer Wählermassen entlarvt. Deshalb mußte man sich auf die Probleme der politischen Institutionen beschränken, und das schloß ein: $\mathrm{Da}$ die Regierung den „politischen Pluralismus“ aufrechterhalte, den „Rechtsstaat" in Kraft lasse, daß die Streitkräfte und die Karabinerieinheiten auch weiterhin die Rolle der "Garantie des demokratischen öffentlichen Lebens" darstellten, daß die Erziehung von der "offiziellen ideologischen Orientation 
unabhängig“ bleibe, daß die „Autonomie der Universitäten“ respektiert werde, daß die Freiheit der Gewerkschaften und sonstiger gesellschaftlicher -rganisationen respektiert werde, daß die Presse- und Meinungsfreiheit aufrechterhalten werde, daß das Heer seine Autonomie behalte und seine Offiziere die Beförderungen und Kommandowechsel bestimmen sollten. Mit Ausnahme der letzten Klausel, waren alle anderen nicht mehr als eine Wiederholung der liberalen Heucheleien, die die Verfassung enthält. Und gerade die letzte Klausel würde das Heer zu einer rechtlich unabhängigen Macht machen, um sich mit den "rechtlichen Mitteln" versehen der Exekutivgewalt entgegenstellen zu können. Die UP hat alle Klauseln akzeptiert, mit Ausnahme der letzten, und die Christ-Demokraten waren nicht in der Lage, auf dieser zu bestehen, denn Allende konnte aufzeigen, daß sie unvereinbar mit den "demokratischen Prinzipien" war, denen sich die Christ-Demokraten verpflichtet hatten.

Die militärische Verschwörung, die in die verïehlte Enıführung des Heereskommandierenden General Schneider und dessen Tod mündete, stellte einen Akt der Verzweiflung des Rechtssektors nach der "Kapitulation“ der ChristDemokraten dar. In diese Verschwörung waren nicht nur Führer der Rechtsparteien (PN und DR) verwickelt, sondern auch Militärkommandanten, die das Vertrauen von Frei besaßen, und selbst repräsentative Vertreter der ChristDemokratie. Aber, obwohl sie hohe Posten innehatten, zeigten die Verschwörer eine mangelhafte Erfahrung auf diesem Gebiet. Die legalistische Haltung Schneiders - der unter den Offizieren ein großes Ansehen hatte zeigte die Größe der Schwierigkeiten, die zu überwinden waren. Die Verwandlung der Entführung in einen Mord zeigte die Unerfahrenheit der Verschwörer. Und der gefühlsmäßige Schock, den der Mord ausgelöst hatte, hat für eine gute Zeit die Putschtendenzen innerhalb der Streitkräfte neutralisiert. Allende wußte das Prestige Schneiders und die Empörung über den Mord auszunützen.

Auf diese Art verliefen die Manöver, mit denen man im November 1970, zwei Monate nach den Wahlen, die Amtsübernahme Allendes zu verhindern suchte im Sande. Die wirtschaftliche Sabotage konnte auch nicht im selben Rhythmus und im selben Umfang fortgesetzt werden; denn die Anwendung dieser Waffe hatte nur einen Sinn, wenn sie eine konsequente Ergänzung in einem Militärputsch gefunden hätte. Sonst wendet sie sich in gewissem Grad gegen seine Urheber. Die Paralysierung der Produktion bedeutet auch einen Ausfall von Gewinnen, abgesehen davon, daß solche Maßnahmen die Regierung direkt herausfordern und zu energischen Gegenmaßnahmen zwingen. Die Bourgeoise mußte sich auf einen Kampf auf längere Sicht einrichten. Die Sabotage mußte verhüllter sein, nuancierter und von Vertrauensbeteuerungen und Mitarbeitsversprechen unterbrochen werden, die es erlaubten, Zeit zu gewinnen und neue Kampfmethoden zu improvisieren.

Selbst die politischen Vertreter der Rechten legten eine Pause ein. Das traditionelle Presseorgan der Reaktion, „EI Mercurio“, wechselte seine Exekutiv- 
leitung aus, um eine „verständlichere“ Linie einzuschlagen, die es erlaubte, die „Würde“ Allendes zu loben und die „Übergriffe“ seiner Anhänger anzuklagen. Die Rechtsparteien, PN und DR, hielten sich provisorisch im Hintergrund. Eine Konsequenz ihrer augenscheinlichen Unpopularität, denn sie hatten sich überzeugen können, daß die Wahlstimmen Alessandris keine Wiedergeburt der alten Rechtsparteien bedeuten. Sie begnügten sich damit, ständig an die Christ-Demokraten zu appellieren, ihren Platz in der antikommunistischen Front einzunehmen. Die zögernde und geteilte Christ-Demokratie wartete $a b$, um Zeit zu gewinnen.

Die Regierung aber konnte keine Zeit verlieren. Sie hatte vor den Massen die Verantwortung übernommen, ein volkstümliches Programm zu verwirklichen, ohne jedoch die nötigen Machtmittel zu besitzen. Selbst wenn man nicht in Rechnung zieht, daß die wirtschaftliche Macht in den Händen der Bourgeoisie lag, wog noch die Tatsache, daß die politische Macht so verteilt war, daß sie alle Schritte der Regierung erschwerte. (Wir beziehen uns hier nicht nur auf den enormen Privatsektor der Wirtschaft, der von den großen Industriemonopolen, Banken und Großgrundbesitz beherrscht wird. Solange die Gesetze der privaten Kapitalakkumulation vorherrschen, ist auch der staatliche Wirtschaftssektor ein Instrument der Bourgeosie.) Im Kongreß war es die Parlamentsfraktion der Christ-Dernokraten, die das Zünglein an der Waage darstellte und die diese Rolle zwischen der Minderheit der äußersten Rechten und der relativen Mehrheit der "Volkseinheit" weiterspielte. Die „Dritte Macht“, die Justiz, ist von der Rechten beherrscht. Und im Heer teilen sich die vorherrschenden Gruppen, von denen diese mit den rechten ChristDemokraten sympathisieren und jene Allende unterstützen, solange er auf dem Boden der Legalität bleibt.

Die Linkskoalition kann keine Zeit verlieren. Heute genießt Allende noch eine ungeheure Popularität und die Massen der Werktätigen begeistern sich an den eröffneten Möglichkeiten, die Herrschaft der großen Ausbeuter zu liquidieren. Wenn aber die Regierung, durch die legalen Hindernisse der bürgerlichen Institutionen gehemmt, ihre Pläne nicht durchführen kann, wird es nicht lange dauern und die Masse wird enttäuscht werden und sich zurückziehen. Dazu kommt noch, daß, wenn die Hebel der Wirtschaftsmacht auch weiterhin in den Händen der inneren und äußeren Großkapitalisten bleiben, die Regierung nicht in der Lage sein wird, der Wirtschaftskrise, die sich anzeigt, zu begegnen, und es werden die Werktätigen sein, die sie zu spüren bekommen. Die Demoralisierung der Regierung und ihrer Stützen würde die Offensive durch die Rechten bedeuten. Deshab dürfte die UP keine Zeit verlieren.

Tatsache ist jedoch, daß die UP Zeit verlor und auch weiter verliert, und daß sie die Zeit dazu verwendet, legalistische Mittel zu finden, die es ihr erlauben würden, die gegenwärtigen legalen Hindernisse zu beseitigen. Innerhalb dieser Strategie wurde der Volksabstimmung ein entscheidender Platz zugewiesen. 


\section{Neu im Verlag des PolitLaden ERLAKGe}

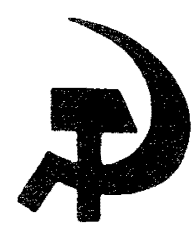

Grigori Sinow jew

Geschichte der KPaSU (B)

- Schulungsmaterial -

240 S. 7,50

Karl Marx/Friedrich Engels

Briefe uiber "Das Kapital"

404 S. 6,00

MEHRWERT

Beiträge zur Kritik der politischen Okonomie. Herausgegeben in Westberlin und Bremen.

Erscheint unregelmäßig.

KAPITALISTISCHE HOCHSCHULREFORM

- Analysen und Dokumente -

Herausge geben von der Marxistischen Gruppe

Erlangen/Niirnberg.

$230 \mathrm{~S} .6,50$

PROBLEME DES KUASSENKAMPFS - Sonderheft 4

$B$ u d e s e h r - Waffe des Kapitals ca. $200 \mathrm{~s} \cdot \mathrm{ca} \cdot 6,00$

IM HERBST 1972

erscheint als Politladen-Druck 4 ein Buch von Christel Neusüb zun Imperialismus, welches nach Darstellung und Auseinandersetzung mit der Leninschen Imperialismustheorie eine Weiterentwicklung der Marxschen Kategorien in bezug auf die Analyse der Weltmarktbewegung des Kapitals enthält.

Als Politladen-Druck 5 erscheint von Karl Held "Marzismus und Sprachwissenschaft".

POIITIADEN GMBH 852 ERIANGEN HINDENBURGSTR.17 
Eine absolute Mehrheit würde erlauben, die Volksmassen direkt über das Grundgesetz zu befragen und würde so das legale Mittel darstellen, die herrschende Legalität zu ändern.

Innerhalb dieser Strategie hatten die Gemeindewahlen, die im April durchgeführt wurden, ebenfalls eine große Bedeutung. In erster Linie gaben sie einen Maßstab für das Kräfteverhältnis der Stimmen nach 4 Monaten Linksregierung an. Für die UP waren sie ein Anzeichen, daß sich der Moment der Einberufung einer Volksentscheides nähert.

Das Wahlresultat war offensichtlich positiv für die Linkskoalition. Die Parteien, die die Regierung unterstützen, erhielten $49,73 \%$ der Stimmen. (Allende hatte $36,3 \%$ in den Präsidentschaftswahlen erhalten, die vor 6 Monaten durchgeführt worden waren.) Die Christ-Demokratie erhielt 25,6\%. (Tomic hatte $27,84 \%$ in den Präsidentschaftswahlen erhalten und die Christ-Demokraten erlangten $36,6 \%$ in den Gemeindewahlen von 1967.) Die Rechtsparteien, PN und DR, erhielten zusammen 21,9\%. (Alessandri hatte $34,98 \%$ erhalten.) Wenn man in Betracht zieht, daß eine bedeutende Fraktion der christ-demokratischen Wähler für das Programm der sozialen Wandlungen der UP gewonnen werden konnte, ist das Resultat für Allende und seinen Genossen befriedigend.

Innerhalb der UP war ein offensichtlicher Linksrutsch zu verzeichnen. Die Sozialistische Partei, die 1967 nur 12\% der Stimmen innehatte, registrierte 1971 22\% (sie wurde von der fünft- zur zweitgrößten Partei des Landes). Dabei ist aber zu beachten, daß die SP nicht nur vom Prestige Allendes profitierte, denn auch andere kleinere politische Gruppierungen, die keine eigenen Kandidaten aufstellten, haben SP gewählt. (Das war der Fall mit MAPU, der Linksspaltung der Christ-Demokraten, welche inzwischen einen Radikalisierungsprozeß durchgemacht hatte. MIR empfahl SP oder KP zu wählen.) Die KP hat mit 16,9\% das Resultat der letzten Wahlen aufrechterhalten. Und die Partido Radical, eine Organisation der Mittelklasse, die die Hoffnung der Mäßigung in der Linksregierung darstellt, hat ebenfalls inre $8 \%$ aufrechterhalten und bewiesen, daß sie innerhalb der Koalition einen zweitrangigen Faktor darstellt.

Das Wahlresultat ist befriedigend, aber es wäre eine Illusion, glauben zu wollen, daß das Problem auf diese Weise gelöst werden kann. Eine Stimmenmehrheit kann sich, wenn sie nicht eine organisierte politische Kraft darstellt, angesichts kleinerer aber organisierter und bewaffneter Einheiten der Reaktion auflösen und zerstreuen. Es ist durchaus kein Fehler, eine legale Strategie ausgearbeitet zu haben, die alle legalen Möglichkeiten ausnutzt und die in der Lage ist, die legalistischen und reformistischen Mittelschichtep zu neutralisieren. Es wäre aber ein Irrtum, das Schicksal der Revolution von diesem Weg abhängig zu machen. Er stellt ein Mittel dar, welches die Sammlung der Kräfte erleichtert, aber kein Mittel, um die Kräfte des Gegners zu liquidieren. Und wenn der legalistische Weg als der entscheidende angesehen wird, droht er in einer Sackgasse zu enden, in der die unvermeidliche Kapitulation wartet. 


\section{Das Programm der "Volkseinheit" und seine Bedeutung im heu§igen Chile}

Was will die Regierung der „Volkseinheit"? Welches sind die Ziele seines Programmes, welches die Bedeutung des Programmes im gegenwärtigen Gesamtbild Chiles und schließlich, wie sieht die Praxis dieses Programms aus? Jegliche Teilanalyse, die das Programm unabhängig von der Dynamik der Klassenkämpfe des Landes sieht, wird nicht in der Lage sein, seine wirkliche Bedeutung zu verstehen.

Wir müssen davon ausgehen, daß der Reformismus des Programmes nicht der für die KP des Kontinents typische „Schlepptau“-Reformismus ist. Die Tatsache, daß sowohl die KP als auch die SP Chiles Parteien mit einem starken Anteil Arbeiter in ihrer Zusammensetzung sind, daß sie unter sich um die Führung innerhalb einer Arbeiterklasse mit langer Kampftradition und breiter Gewerkschaftsorganisation konkurrieren und daß sie schließlich beide die bürgerlich reformistische Alternative, die von den Christ-Demokraten vertreten wird, bekämpfen müssen, hat dazu beigetragen, daß das Programm wesentlich anti-kapitalistische Züge trägt, die sich stark von den pro-bürgerlichen Idealisierungen, die in der brasilianischen oder argentinischen KP z. B. vorherrschen, unterscheidet.

Das Programm der „Volkseinheit" beschränkt sich nicht auf die klassische Kritik des Imperialismus und des Latifundiensystems, die vom Gesichtspunkt der „kapitalistischen und industrieflen Entwicklung" und der „demokratischbürgerlichen" oder "nationalistischen und antifeudalen Revolution" gemacht werden. Es charakterisiert Chile als ein,, kapitalistisches, vom Imperialismus abhängiges Land" und anerkennt, daß "die ,Sichauslieferung der nationalen Monopolbourgeoisie an den Imperialismus, nichts anderes als eine Konsequenz der Entwicklung des Weltkapitalismus" darstellt. Hier wird dann freilich die „mittlere Bourgeoisie“, die nicht monopolistisch organisiert ist, ausgeklammert, aber das führt das Programm nicht dazu, einen „Weg des nationalen Kapitalismus" oder ähnliches vorzuschlagen, wie das bei den meisten KPs des Kontinents de Fall ist. Im Gegenteil, seine Kritik richtet sich ganz gegen das kapitalistische Regime. ,In Chile regiert man und macht die Gesetze für Wenige, für die großen Kapitalisten und ihre Gefolgsleute, für die großen Gesellschaften, die unsere Wirtschaft beherrschen, für die Latifundienbesitzer .... Die Herren des Kapitals, sie interessieren sich dafür, immer mehr zu verdienen und nicht, die Bedürfnisse des chilenischen Volkes zu befriedigen". Und nachdem konkrete Beispiele des Mechanismus der Ausbeutung und des Erhalts der Klassenprivilegien gegeben werden. endet die Analyse der Situation mit der Feststellung: „Die einzige wirkliche Alternative für das Volk und das heißt, die grundlegende Aufgabe, die die Regierung des Volkes zu bewältigen hat, ist die, die Herrschaft der Imperialisten, der Monopole, der Latifundienoligarchien zu beenden und den Aufbau des Sozialismus in Chile zu beginnen“. Selbst das Gewäsch von der „Regierung des Volkes“ kann die Bedeutung der vorgezeichneten Ziele nicht annullieren. 
Wenn das Programm der "Volkseinheit" nur nach dem eben zitierten Teil (Analyse der allgemeinen Lage und Charakter der großen wirtschaftlichen Umwandlungen) beurteilt werden könnte, würden wir nicht zögern, es revolutionär zu nennen, trotz populistischer Unbestimmtheiten, die dem Dokument eigen sind. Der reformistische Charakter des Dokumentes ist aber hauptsächlich durch seine Strategie des Kampfes um die politische Macht bestimmt.

Grundsätzlich sucht die politische Strategie des UP-Programms, die Volksdəmokratie innerhalb des bürgerichen Staates einzuführen. Wir sagen hier "Volksdemokratie", mit all der Zweideutigkeit des Wortes, aber die Bezeichnung gibt nur die Unbestimmtheiten der Terminologie des Programmes wieder. Dieses sagt, daß die revolutionären Umwandlungen nur möglich sein werden, ,falis das chilenische Volk die Macht in seine Hände nimmt", und definiert lann die Volksmacht als die der „Werktätigen, Bauernschaft und fortschrittlichen Sektoren der Mittelschichten aus Stadt und Land". Das Organ, das die "Volkssouveränität" verkörpern soll, wird die "Volkskammer" sein, die durch die fortgeschrittensten Methoden einer revolutionären Demokratie gewählı werden wird, die aber keinerlei neuen Klassencharakter enthält.

Die populistische Zweideutigkeit wird ergänzt von einer graduellen Auff́assung der Machtergreifung. Es handelt sich nicht darum, einen Staat durch einen anderen zu ersetzen. Es handelt sich nicht darum, den bürgerlichen Staat zu zerstören und einen sozialistischen an seine Stelle zu setzen. Für das Programm handelt es sich lediglich darum, eine größere Beteiligung der Massen an den Staatsorganen anzuregen. Die Organisationen des Volkes „werden aufgefordert werden, in den Sektoren zu intervenieren, die ihnen durch Entscheidung der Machtorgane zugeteilt werden“. Das Dokument sieht verschiedene Formen der demokratischen Mitbestimmung in öffentlichen Ämtern und Betrieben vor. Das höchste Gerichtstribunal soll von der Volkskammer zusammengesetzt werden. Was die Streitkräfte betrifft, so ist das Programm schon vorsichtiger. Es definiert die neuen Aufgaben (Verteidigung der nationalen Souveränität gegen die imperialistische Bedrohung und nicht mehr die Unterdrückung der Massen), nimmt aber keinerlei Bezug auf Maßnahmen, die zu nehmen wären, um den Charakter der Streitkräfte zu verändern; sagt nichts über den reaktionären Charakter der militärischen Hierarchie, ihre Tradition usw. aus.

In summa, infolge der Zweisinnigkeit des Programmes, was die politische Macht anbetrifft, müssen wir den praktischen Ablauf der Ereignisse verfolgen, um zu sehen, inwieweit die Anwendung dieser volksdemokratischen Mittel die bürgerliche Herrschaft brechen kann. Es ist eine quantitative und qualitative Frage. Die wirklichen Maßnahmen geben sich nicht in einem Vakuum, sie setzen sich im Feuer des Klassenkampfes durch. Wenn einige der grundlegenden Maßnahmen auf einmal und mit genügendem Gewicht durchgesetzt werden, um im gegebenen Moment das Reaktionsvermögen der Bourgeoisie zu brechen, dann können wir von revolutionären Möglichkeiten sprechen. 
Aber wenn die gutgemeinten „revolutionären“ Umwandlungen auf längere Sicht programmiert werden, ist es wahrscheinlicher, daß dieser Prozeß vorher durch die konterrevolutionäre Intervention der Bourgeoisie unterbrochen wird.

\section{Die ersten sechs Monate}

Nach Ablauf der ersten sechs Monate der Regierung Allende kann man feststellen, daß diese eine Reihe volkstümlicher Maßnahmen getroffen hat, die innerhalb der alten Institutionen zu verwirklichen waren, daß aber von den wirklich grundlegenden Maßnahmen lediglich die Vollstreckung einiger geplant sind.

Das unmittelbare Resuliat der vollzogenen volkstümlichen Maßnahmen bestand hauptsächlich darin, eine neue Regierungsorientierung zu demonstrieren. Die Möglichkeiten der bürgerlichen Institutionen ausnutzend, hat die Regierung Maßnahmen gegen Privilegien und Mißbräuche hochgestellter Bürokraten und Kapitalisten unternommen - Strafverfolgungen spekulierender Bankiers, steuerflüchtiger Unternehmer, bewaffneter Latifundienbesitzer, korrupter Beamter und Beseitigung des Mißbrauchs öffentlicher Gelder. Hier wurde zum erstenmal und auf konsequente Weise das bürgerliche Gesetz gegen die Bourgeoisie angewendet.

Was die Grundbesitzrechte betrifft, so ist die alte chilenische Gesetzgebung äußerst generös mit denjenigen, die fremdes Land besetzen, aber äußerst rigoros denen gegenüber, die versuchen, das so verlorene Land durch Gewaltanwendung sich wieder anzueignen. Diese Gesetzgebung wurde geschaffen, um die Besitznahme der Ländereien der Mapuche-Indianer durch die weißen Siedler zu erleichtern. Allende hat diese Gesetze benützt, um schwere Sirafen gegen die Latifundienbesitzer zu verhängen, die den Bodenbesetzungen der Bauern und Landarbeiter mit Waffengewalt zu begegnen suchten; gleichzeikig hatîe er die größte Nachsicht den Bauern gegenüber. Auch als er linke Genossen, die in Bankexpropriationen zur Zeit Freis verwickelt waren, begnadigte, lobte Allende ihre guten Absichten (und kritisierte ihre Methoden), und verglich ihren Mut mit der Feigheit derjenigen, die sich sicher auf der anderen Seite des Bankschalters eingenistet haben, um das Volk zu berauben. Am nächsten Tag, wie um seine Anspielung deutlicher zu machen, wurde ein Haftbefehl gegen einen lokalen Großbankier ausgestellt, der Devisenspekulationen gemacht hatte. Eine andere Maßnahme, die Widerhall hatte, war die Auflösung der Karabinierieinheit - einer Polizeitruppe die auf die Unterdrückung von Massenbewegungen gedrillt war.

Gleichzeitig wurden Maßnahmen für die "Volkswirtschaft" unternommen: Allgemeine Erhöhung der Löhne und Gehälter (ungefähr des Doppelten der Erhöhung der Lebenshaltungskosten im selben Zeitabschnitt), Preisstopp für lebensnotwendige Waren, Mietstopp, kostenlose ärztliche Versorgung, Verbilligung der Mahlzeiten in Restaurants und Kantinen. Auch gelang eine fast vollständige Beendigung der Inflation. 
Auf dem Lande wurde die Agrarreform weitergetrieben. Am 19. Dezember kündigte die Corporacion de la Reforma Agraria (CORA) an, daß sie $53 \mathrm{Be}-$ sitze mit einem Total von 24000 Hektar übernommen hat. Am 22. Januar kamen noch 32 Enteignungen dazu und Ende Februar 46 weitere. Angesichts der Panik, die sich unter den Großgrundbesitzern ausbreitete, die anfragten, wo die Grenzen der Reform liegen, erklärte der Vize-Präsident der CORA, daß die Regierung die Absicht habe, allen Privatbesitz an Boden aufzuheben und den Bauern das Anrecht auf das Produkt ihrer Arbeit zu geben, wobei über die zukünftige Eigentumsform von den Bauern selbst entschieden werden soll. Er kündigte an, daß es noch ungefähr 3500 bis 4000 Enteignungen geben werde. Der Landwirtschaftsminister fügte hinzu, daß aller Besitz, der nicht als klein oder mittelgroß angesehen werden kann, enteignet werden wird. Das größte Hindernis dieser Maßnahme - sagte der Vize-Präsident der CORA - wären die vorauszusehenden hohen Kosten der ganzen Operation. („El Mercurio“, vom 2. und 3. 1. 71.) Man darf aber nicht aus den Augen verlieren, daß die Beschleunigung des Enteignungsprozesses sich aus dem Druck von unten ergab, der Besetzung der großen Ländereien durch die Bauern, die nicht auf den legalen Weg warteten. Anfang Februar existierten ungefähr 250 Großgrundbesitze im Lande, die von den Bauern besetzt worden waren. Die große Mehrzahl wurde von den Bauern aus eigener Initiative enteignet und so vollzogene Tatsachen geschaffen, dië die Regierung respektieren mußte.

Was die internationalen Beziehungen betrifft, so hat die Wiederaufnahme der diplomatischen Beziehungen mit Kuba, China, Nordkorea und die Aufnahme der Beziehungen mit der DDR eine Lage geschaffen, die der chilenischen Außenpolitik eine neue Richtung gab.

Es ist aber auch klar, daß all diese Maßnahmen üb.er gewisse Grenzen nicht hinausgehen. Sie befreien die Wirtschaft des Landes noch nicht von seiner bürgerlichen Struktur. "Sie suchen lediglich die Möglichkeiten zu nutzen, die eine Linksregierung aus einem bürgerlichen Machtapparat herausholen kann. Und es ist auch klar, daß diese Widersprüche, die so geschaffen wurden, eine Frist setzen - und keine allzu lange - innerhalb derer sie gelöst werden müssen. In dem Maße, in dem die Wirtschaft sich noch laut Gesetzen der kapitalistischen Akkumulation weiterentwickelt, werden die mit den besten Absichten geplanten Maßnahmen für eine Neuverteilung der Einkommen und der Abschaffung von Privilegien und Willkürakten an den unumgänglichen Gesetzen des Regimes scheitern. Die Maßnahmen sind wichtig, weil sie einen Zustand vor den Augen der Massen enthüllen und neue sơziale Mö.glichkeiten aufzeigen. Aber gerade aus diesem Grunde entmutigen sie die privaten Investitionen und provozieren auf Sicht Stockungen und Krisen der wirtschaftlichen Tätigkeit. Damit dieser Typ von Reformen keinen wirtschaftlichen Stillstand hervorruft, müssen sie von einer globalen Politik der Ersetzung der kapitalistischen Akkumulation durch eine sozialistische, als grundlegender Entwicklungsprozeß ergänzt werden. 
Die unvermeidlichen Verstaatlichungen, die notwendig sind, um eine sozialistische Planung in Angriff zu nehmen, sind im großen und ganzen über das Stadium des Programmierens nicht hinausgegangen. Es wurden einige große Betriebe verstaatlicht, welche die Regierung direkt provoziert. hatten, indem sie die Produktion einstellten, die Löhne zurückhielten und begannen, Arbeiter zu entlassen. Und die großen Verstaatlichungen der Minen und Banken wurden angekündigt. Am 21. Dezember verkündete Allende öffentlich sein Programm der Minenverstaatlichung, das eine Verfassungsreform notwendig macht: Der Staat erhält die absolute Verfügungsgewalt über Minen und Rohstoffreserven; Privatpersonen können nur Konzessionen erhalten. Die „groBen Minen", die noch der Definition harren, werden alle verstaatlicht; die Entschädigungen werden von der Controlaria General de la Republica festgesetzt werden, mit Berufungsmöglichkeit an einen Gerichtshof, der von der Regierung geschaffen wird. Die Entschädigungen werden in dreißig Jahren abgezahlt werden. Am 31. Dezember hat die Regierung die Verstaatlichung der Kohlenminen angekündigt. Am selben Tag verkündete Allende seine $A b-$ sicht das ganze Banksystem zu verstaatlichen.

Was man ganz klar sehen kann ist die Tatsache, daß die grundlegenden Maßnahmen alle dem legalen Wege entsprechen. Inzwischen geht die Entwicklung schleichend vor sich mittels eines Systems der Entschädigungen, die innen jede revolutionäre Wirkung nehmen, denn sie lassen in den Händen der Kapitalisten die Mittel, die der Staatskasse fehlen.

Diese Analyse der praktischen Anwendung des Regierungsprogrammes beendend, kommen wir zur Schlußfolgerung, daß seine Bedeutung darin bestand, eine größere Dynamik der Kämpfe ausgelöst zu haben. Die Massenbewegung, die schon zu Zeiten Freis im Wachsen war, hat sich noch weiter ausgebreitet, als sichtbar wurde, daß das Instrument der bürgerlichen Reaktion neutralisiert war. Die einfache Tatsache, daß die Bourgeoisie nicht mehr auf die Regierung rechnen konnte, um die Kampfbewegungen der Arbeiter zu unterdrücken, die Tatsache, daß die Organisationen der Werktätigen sich jetzt ungehindert vervielfachen und über das Land ausbreiten konnten, hat der Massenbewegung eine außerordentliche Stärke verliehen. Die Inbesitznahme der Ländereien wurde zu einer Routineaktion, und als Konsequenz dessen begannen im ganzen Land die Besetzungen von Wohnhäusern, Bauten und Fabriken zu sprießen. Und gerade das fürchtet die Reaktion am meisten. Es ist diese Dynamik der Massenbewegung - gefördert durch die einfache Tatsache der Anwesenheit einer Regierung, deren Macht von der Unterstützung der Werktätigen abhängt - die veranlaßt, daß sich sowohl die lokale Bourgeoisie wie auch die Imperialisten sich mit der Regierung der „Volkseinheit" nicht abfinden können.

Die größte Gefahr für die weitere Entwicklung im revolutionären Sinne besteht in den bürokratisierenden Tendenzen, die ihr innewohnen. Eine „leistungsfähige" technische Arbeitsgruppe plant die Ausführung der Reformen. Dem "Volk“ wird die Rolle zugewiesen "die Regierung zu unterstützen" ge- 
gen die Rechtsgefahr. Und diese Verwalter verlieren leicht die Geduld mit Masseniniativen, die im Programm nicht vorgesehen sind. Die Regierung kündigt an, daß sie beabsichtigt die „Komitees der Volkseinheit“ zu dynamisieren, aber lediglich, damit sie die Maßnahmen, die „von oben“ genommen werden, unterstützen. So ist die Regierung unfähig, eine wirksame politische Kraft zu schaffen, die sich von einer echien revolutionären Masseninitiative nährt.

Auf jeden Fall jedoch öffnet das Programm und die Praxis der UP einen breiteren Weg für den revolutionären $P$ rozeß in Chile. Die reformistischen Maßnahmen sind für die herrschende Klasse unannehmbar, weil die geschaffene breite Demokratie ihr nicht mehr die Kontrolle des Prozesses garantiert. Die Aufgabe der revolutionären Linken besteht gerade darin, diese Lage so auszunützen, daß über den „Bruchpunkiّ“ hinweg kein Weg mehr zurück führt.

Diese scheinbare „politische Ruhe" wurde nur Anfang des Jahres unterbrochen, als der Oberste Gerichtshof die Eröffnung eines Prozesses gegen einen Senator der DR untersagte, obwohl dieser tief in den Mord am General Schneider verstrickt gewesen war. Während Gewerkschaft, Studentenverbände, linke Zeitungen usw. angemessen reagierten, hat sich die Rechte für den Obersten Gerichtshof eingesetzt, dessen „Autonomie“ gefährdet sei. Anschließend hat derselbe, vom Gerichtshof beschützte Senator öffentlich eine antikommunistische „Bürgerfront“ vorgeschlagen, um der Regierung „auf allen Gebieten“ Opposition zu leisten. Er rief auch die DC auf, damit sie den ihr zustehenden Platz in diesem Kampf einnähme. Zwei terroristische Attentate enthüllten zwei Tage später den Charakter dieser Offensive. Und dennoch ging diesem Unternehmen alsbald die Luft aus, da die Unterstützung der DC ebenso fehlte wie sichere Bastionen, die über die kleinen Gruppen bewaffneter Latifundienbesitzer des Südens hinausgingen.

Am 22. Januar brachten die Abgeordneten der PN und der DR eine Verfassungsklage gegen den Justizminister ein. „Angriffe auf die Unabhängigkeit der Justiz“, die „illegalen“ Ausfälle von aktiven Revolutionären, Gesetzesübertretungen und fehlende Ordnung besonders auf dem Lande waren die Anklagepunkte. Die Rechte zwang somit die DC zu einer Stellungnahme. Mit 8 gegen 4 Stimmen lehnte der Rat der Christ-Demokraten die von der äußersten Rechten vorgeschlagene Linie ab. Mit dieser Entscheidung gab die Partei zu verstehen, daß sie die „illegalen“ Akte der Regierung woh! kenne, daß aber Allende dafür verantwortlich seit. Überdies vermeide die Partei alles, um die Krise dadurch zu verschärfen, daß sie sich der ,antidemokratischen Manöver" von Gruppen „in oder außerhalb der Regierung“ bediene und folge deshalb dem Aufruf der äußersten Rechten nicht.

Aber die äußerste Rechte benötigt die Unterstützung durch die DC. Zugleich will sie der herrschenden Klasse beweisen, daß das Zögern der Partei Eduardo Freis für den fehlenden Widerstand gegen den „kommunistischen Vor- 
marsch" verantwortlich sei. Die DC ihrerseits setzte alies daran, um sich als die einzige Alternative zum „Marxismus“ auszuweisen, die allen gefährlichen "Abenteuern" abgeneigt und fähig sei, durch eine "schmerzlose" Ablösung der UP die Radikalisierung zu bremsen.

In den Wahlen, die im April notwendig wurden, um den vakanten Sitz Allendes im Senat neu zu besetzen, hat die DC einen Kandidaten ihres rechten Flügels aufgestellt, aber zugleich jede Möglichkeit einer formellen Vereinbarung mit der PN und der DR ausgeschlossen. Dies war keine einfache Unentschlossenheit.

Vielmehr hat sie versucht, sich als die einzige, "verantwortungsbewußte" Opposition zu erweisen. Diese politische Position spiegelt die soziale Basis der Partei wider, die sie vor allem in den Mittelklassen, den rückständigen Massen und in der städtischen Bourgeoisie hat. Diese Position führie zu einer internen, beständigen Spannung in der Partei: die "Linke" wird von der mit den Reformen einverstandenen Basis, die „Rechte“ von der durch die Reformen gefährdeten Basis vorwärtsgetrieben. Der Präsident der christlichdemokratischen Jugend erklärt jeden Tag, daß eine „grundsätzliche Übereinstimmung" zwischen der DC und der UP bestehe: der Kampf gegen die kapitalistischen Strukturen. Aber als es um die von der UP eingeleitete Konzentration auf dem Lande ging, haben andere Abgeordnete der DC gegen diese „willkürlichen Besetzungen“ des Landes protestiert. Auf dem Parteitag im Dezember hat sich die Partei beinahe gespalten. * Die neugebildete Leitung hat folgende Kompromißformeln gefunden:

1. Es gibt nur zwei dynamische Kräfte in der chilenischen Gesellschaft, die Marxisten und die DC, weil die Verteidiger kapitalistischer Privilegien keine akzeptable Alternative darstellen.

2. Die DC unterstützt die Reformen, die sie selbst 1964 begonnen hat; aber sie vertritt unterschiedliche Auffassungen über Demokratie und ökonomische Entwicklung.

Die Stärke der DC ist ein vollkommener Reflex des schwankenden politischen Gleichgewichts im Land und auch der versöhnlerischen Tendenzen, die augenblicklich die Klassenkämpfe noch beschwichtigen. Deshalb sehen es sowohl die Rechte als auch die Linke als eine ihrer wichtigsten Aufgaben an, die DC zu spalten. Nach dieser Spaltung stünden sich die antagonisti-

*) „Le Monde" meldet in ihrer Ausgabe $(3 / 8 / 71)$, daß 6 Abgeordnete und die Mehrheit des Zentralausschusses des Jugendverbandes der Christ-Demokraien die Partei verlassen haben, um die" "Christlichen Linken" zu gründen, die mit der Volkseinheit zusammenarbeiten wollen. Die Spaltung protestierte gegen die Zusammenarbeit der Christ-Demokraten mit den Rechtsparteien, die anläßlich der Neuwahlen im Distrik Santiago eingeleitet wurde, in denen der Kandidat der "Volkseinheit" mit knapper Mehrheit geschlagen worden ist. Über das Ausmaß der Spaltung kann man sich noch kein Urteil bilden. 


\section{Rotbücher}

Peter Brückner/Alfred Krovoza Staatsfeinde

Innerstaatliche Feinderklärung in der BRD. Die Autoren versuchen die Momentaufnahme einef BRD, in der die UnverhältnismäBigkeit der Mittel den Verhältnissen entspricht.

ROTBUCH 40.112S.,DM 4,50 (3,50)

Gauche prolétarienne Volkskrieg in Frankreich?

Strategie und Taktik der GP

Dieses Buch zeigt den latenten Faschismus, der sich hinter der Fassade desRechtsstaatesversteckt und die Möglichkeit der Gegenwehr. ROTBUCH 34.160S., DM 6,50 $(5,50)$

\section{Der erzwungene Kapitalismus}

Klassenkämpfe in den Westzonen 1945-48. Von Ute Schmidt/Tilman F:chter. Die Geschichte der erzwungenen "Entpolitisierung" der ersten 3 Nachkriegsjahre und der. verhinderten Klassenkämpfe. Zahlreiche Dokumente.

ROTBUCH 27.180 S., DM 6,50 $(5,50)$

Ulrike.M. Meinhof:

\section{Bambule}

Fürsorge - Sorge für wen?

Nachwort Klaus Wagenbach. "SchlieBlich gibt es das Rotbuch 24, lesenswert, aufschluBreich als Film immer noch nicht gesendet..."H.Böll.

ROTBUCH 24. 108 S., DM 4,50 $(3,50)$

\section{Arbeiter und Apparate}

Bericht des Kollektivs HispanoSuiza, französische Arbeiter, über ihre Praxis 1945-70. Tonbandprotokolle und Berichte aus einem $\mathrm{Be}$ trieb.

ROTBUCH 30. 160 S., DM 6,50 $(5,50)$

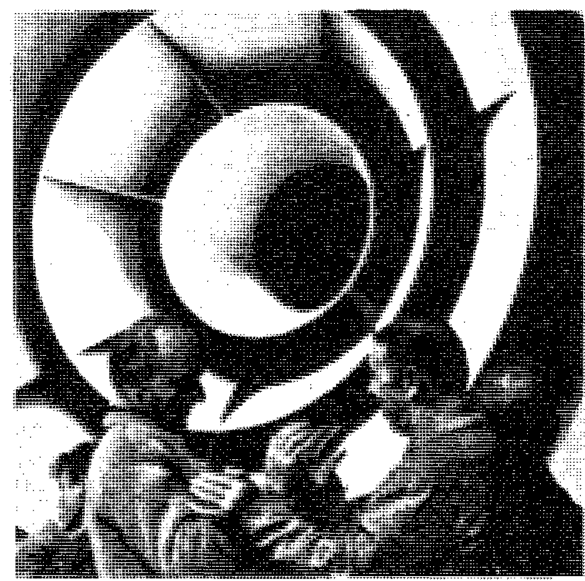

BETRIEBSFIBEL

Vorschläge zur politischen Arbeit in der Produktion von Berni Kelb. Mit einem Anhang von Jörg Hufschmid über Bilanzanalyse. In der Form eines Briefs berichtet Kelb über Möglichkeiten eines Einzelkämpfers, Organisierung von $\mathrm{Be}$-triebsgruppen, Agitation in der Freizeit, Flugblätter, Verhältnis zu den Gewerkschaften.

ROTBUCH 31. 72 S., DM 3,50 (2,50)

Jährlich etwa 8 meue ROTBÜCHER. Jedes ROTBUCH im Abonnement 1 Mark billiger. Abonnieren Sie in Ihrer Buchhandlung oder direkt: Verlag Klaus Wagenbach, 1 Berlin 31, Jenaer Str.9. Falls Sie unsere Bücher in einer Buchhandlung nicht erhalten, schreiben Sie uns, wir nennen Ihnen eine andere.
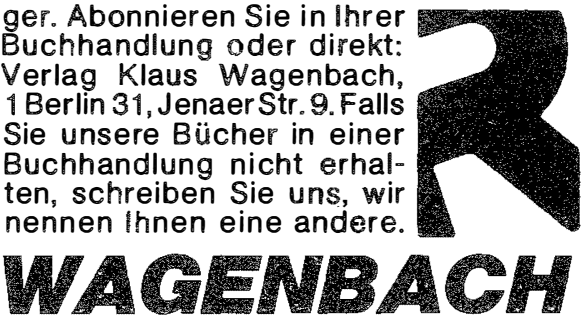
schen Pole der chilenischen Gesellschaft zum Entscheidungskampf gegenüber.

Es verrät die Schwäche der Bourgeoisie, daß sie der DC folgt. Denn nur eine schwache Bourgeoisie kann die verschwommene, antikapitalistische Ideologie der DC akzeptieren. Solange sie nicht über wahre Offensivwaffen verfügt, bedient sie sich dieser künstlichen Waffen. Sobald die Bourgeoisie sich aber stark genug fühlt, ihre Rechnung mit der Linken zu begleichen, wird sie eine andere, politische Kraft benötigen. Es ist nicht auszuschließen, daß dann eine wichtige Fraktion der DC und sogar die Mehrzahl ihrer augenblicklichen Führer sich wieder in leitenden Positionen befinden werden.

Aber diese Entwicklung setzt nicht nur tiefe innere Brüche in der Partei voraus, sondern auch gesellschaftliche Veränderungen von großer Reichweite. Breite Schichten des Volkes folgen gleichfalls der DC, die sich nicht allein aus Beamten, privilegierten Angestellten und kleinen Eigentümern zusammensetzen, die in der Gesellschaftsstruktur eine Zwischenposition einnehmen, sondern auch aus ländlichen und städtischen Arbeitern. Letztere für sich zu gewinnen, muß Aufgabe der Linken sein. Als Mittel kommen nicht Vereinbarungen mit den rechten Führern der DC oder Versprechungen wie „Respekt vor der Legalität“ in Frage, sondern nur geduldige Arbeit an der Basis. Diese wäre auf die Mittelschichten auszuweiten, müßte deren antikapitalistische Disposition ansprechen und ain konkreten Fällen die Verhüllungsideologie der DC als Verteidigungsinstrument kapitalistischer Interessen entschleiern.

\section{Der Mord an Zujovic}

Die Ermordung des christlich-demokratischen Führers Zujovic im Juli hat die Fronten verhärtet und zu einer Offensive der Rechten geführt, die erfolgreicher als die erste war. Bislang hat die Regierung die Oberhand in den Konflikten mit der Rechten behalten. Doch der Mord an Zujovic hat diese Position ernsthaft erschüttert. Die Attentäter gehörten zur VOP (organisierte Vorhut des Volkes), einer kleinen Jugendorganisation, die aus de MIR hervorgegangen ist. Schon unter der Regierung Frei hatten sie keine politische Linie außer schlecht vorbereiteten Überfällen. Unter der Regierung Allende meinten sie, keine Abstriche an ihrer Taktik machen zu müssen. Durch ihre Absicht, möglichst schnell eine Entscheidung herbeiführen zu wollen, haben diese Abenteurer die Lage für die Linke entscheidend verschlechtert.

Die reaktionärsten Teile der DC haben von der Erregung über den Mord profitiert und eine Verhärtung der Position ihrer Partei gegenüber der Regierung erreicht. In der Abgeordnetenkammer bildeten die Christ-Demokraten ohne Schwierigkeiten eine Koalition mit der äußersten Rechten und erreichten damit die Ablösung des Parlamentspräsidenten, der bis jetzt von der UP gestellt wurde, durch einen anderen Oppositionellen. Außerdem haben die Christ-Demokraten darauf bestanden, $d a ß$ sie der Ausschreibung von tausend neuen Stellen für Polizisten erst dann zustimmen würden, wenn die Regie- 
rung die bewaffneten Gruppen auflöse. Damit steht die Regierung vor der Alternative, entweder mit der aus Christdemokraten und Rechten bestehenden Mehrheitsopposition zu ringen oder aber den Kampf gegen die revolutionäre Linke und ihre bewaffneten Organisationen aufnehmen zu müssen.

Für die politische Ausrichtung der DC wie auch der UP bleiben die Schwankungen der Mittelklasse ausschlaggebend. Hatte ihre Empörung bei der Ermordung des Generals Schneider und ihr Legalismus die Position von Allende gestützt, so kam diese Einstellung im Fall Zujovic der Rechten zugute.

Die Klärung der politischen Fronten findet unter Bedingungen statt, die für die Revolutionäre ungünstig sind. Denn gerade jetzt haben die konservativen Teile der Regierung eine Reihe von Maßnahmen beschlossen, die zu Konflikten mit der revolutionären Linken und einigen kämpferischen Teilen der Massenbewegung geführt haben. Im Mai ergriff die Regierung repressive Maßnahmen, um ihre Autorität gegenüber den „illegalen“ Initiativen der Bauern und "Pobladores" zu stärken. Es gibt zwar „Ekzesse" bei der Besetzung von Ländereien, weil vorwiegend kleine wenig widerstandsfähige Ländereien besetzt werden, was schwerwiegende ökonomische Konsequenzen und eine vorzeitige Verschärfung politischer Probleme nach sich zieht; doch die Ursache für die „Ekzesse“ liegt im Bürokratismus der Regierung, der der revolutionären Energie der Massen keine Richtung geben kann. Auf einen Nenner gebracht: Die Intervention der Regierung ist noch nicht diejenige einer proletarischen Regierung, die ultralinken Anarchismus bekämpft, sonder die eines bürgerlichen Staatsapparats. Diese Maßnahmen der Regierung sind gewissermaßen Dienstleistungen an Bourgeoisie und Armee, die man nicht erschrecken will.

Schließlich ist das gegenwärtige Gleichgewicht nur eine stillschweigende „Übereinkunft“. Die UP kann nicht weiter gehen, da sie weder über genügend politische Macht noch - und das ist der zentrale Punkt - über eine revolutionäre Armee verfügt; die Rechte kann ihre Offensive vertagen, solange die UP die wichtigsten Institutionen des Regimes respektiert.

Es wird Aufgabe der Revolutionäre sein, die politischen und materiellen Bedingungen zu schaffen, die einen Ausweg aus der gegenwärtigen Sackgasse ermöglichen.

\section{Die Massenbewegung}

Damit die Linke im „revolutionären Durchbruch“ erfolgreich sein kann, braucht sie eine eigene Armee. Das heißt aber - und das ist die andere Seite desselben Problems - daß die arbeitenden Massen ihren Organisationsgrad und die Stärke ihrer Kämpfe derartig steigern müssen, daß sie die revolutionäre Armee herausbilden, die dann die revolutionäre Umwandlung des Regimes stützen wird. Denn die Bildung einer "revolutionären Armee“ ist weder ein Verwaltungsakt noch eine rein technische Angelegenheit, die 
von der Dynamik der Massenbewegung isoliert werden könnte. Vielmehr hat die revolutionäre Armee ihre Grundlage und Quelle in den revolutionären Klassen, die sich für ihre historischen Interessen erheben. Ihre Aufstellung ist entweder das Produkt der politischen Arbeit unter den breiten Massen, die sich der Notwendigkeit des bewaffneten Kampfes bewußt werden, oder der spezifischen Arbeit der Avantgarde, die die Organisationsformen schafft, die jeder Phase des Kampfes ensprechen.

Was kennzeichnet die Massenbewegung in Chile? Welche Politik verfolgt die Linke, um eine wirklich revolutionäre Kraft heranzubilden? In Chile ist die wichtigste Kraft das Proletariat der Industrie und der Bergwerke. Die Linie seiner politischen und gewerkschaftlichen Organisationen bestimmt die Politik der UP in ihrer Stärke (Organisation, Präsenz in den Schlüsselsektoren der Wirtschaft, Stabilität) wie auch in ihrer Schwäche (Reformismus, Ökonomismus). Die Tradition der Kämpfe hat ein Bewußtsein als „Klasse an sich“ geschaffen, das sich in der Verteidigung ihrer unmittelbaren Interessen äuBert. Dieses Bewußtsein schlägt sich in der Wahl sozialistischer Kandidaten und in dem Zusammenschluß in Organisationen nieder, die der Verteidigung ihrer unmittelbaren Interessen dienen. Dieses „Bewußtsein“ hat jedoch zwei schwerwiegende Grenzen.

1. Es kristallisiert sich für unmittelbare Interessen und für einen reformistischen Kampf heraus; denn sozialistisch wählen, heißt noch nicht, bereit zu sein, für die sozialistische Revolution zu kämpfen. Bei näherer Betrachtung beschränkt sich dieses Bewußtsein auf eine legalistische Klassensolidarität, auf eine Interessenvertretung im Rahmen des Regimes.

2. Als Folge dieser ökonomistischen Politik, die breite Schichten nicht befriedigen kann, breiten sich Organisationsgrad und Klassenbewußtsein nicht außerhalb der kampfkräftigsten Teile der Arbeiterklasse aus, die dem System Konzessionen abringen können und in den Organisationen des Proletariats dominieren.

Das Proletariat hat massenhaft für Allende gestimmt. In den Bergarbeiterzentren hat Allende 2,5 bis 8 mal mehr Stimmen als seine Gegner erhalten. Selbst nach den Wahlen blieb das Proletariat in "Komitees der Einheit des Volkes" mobilisiert, um die ordnungsgemäße „Wachablösung“ zu überwachen. Aber anschließend wurde es demobilisiert. Als im Dezember die UP das Volk aufrief, um inm die Nationalisierung der Bergwerke bekannt zu geben, folgten nur 20000 dem Aufruf. Freilich heißt das nicht, daß das Proletariat die Regierung Allende nicht mehr unterstützt. Die Passivität und das Warten auf „sozialistische Taten" des „Genossen Präsidenten" waren die Folgen der parlamentarischen Form der Politik.

Jedoch die Bedingungen der Gesellschaft selbst haben die Keime für neue Interventionsformen der Arbeiterbewegung entwickelt. Allein die Tatsache, $\mathrm{da} B$ eine sozialistische Regierung besteht, hat zu einer unnachgiebigen $\mathrm{Hal}-$ 
tung der Arbeiterklasse in Lohnkämpfen geführt. Die Arbeiter haben, wohl wissend, daß die Unternehmer nicht mehr ungehindert zu repressiven Maßnahmen greifen können wie früher, mit größerer Härte ihre Lohnstreiks durchgeführt; und als die Unternehmer sich auf ihre Ausgaben beriefen oder mit dem Ausstand drohten, haben die Arbeiter den Eingriff der Regierung gefordert. Am 8. Dezember schlossen die Regierung und die Gewerkschaftszentrale ein Abkommen, nach dem sich die Arbeiter verpflichten sollten, die Produktion zu steigern, während die Regierung versprach, für ökonomische Verbesserungen und die Beteiligung der Arbeiter an politischen Entscheidungen zu sorgen. Der „El Mercurio“ jubilierte über diesen Kompromiß und erklärte, dies sei ein geeignetes Mittel, um die Streiks zu beenden. Das war eine falsche Rechnung. Denn die Lohnerhöhungen und die Erklärungen der Regierung haben das Selbstbewußtsein des Proletariats nur noch erhöht. Seit Januar nimmt die Zahl der Fabrikbesetzungen immer schneller zu. Es scheint, als ob die radikalen Aktionen der Landarbeiter und der „Pobladores sin casa" schließlich auch auf das Industrieproletariat übergegriffen hätten. Arbeitslose besetzen stillgelegte Bauten, Angestellte die Betriebe. Die Bilơung von Kampforganen in den Betrieben und anderen Arbeitsstätten kann die Grundlage für eine neue Dynamik der ganzen Klasse sein.

Angesichts der Regierungskampagne für eine Produktionssteigerung gewinnen Aktionen wie die der Arbeiter von Proinsa, einer englischen Stahlfabrik, an Bedeutung. Sie haben einstimmig beschlossen, nur dann die Produktion zu erhöhen, wenn ihnen ein Kontrollrecht eingeräumt wird. Die von ihnen besetzte Fabrik haben sie erst dann verlassen, als die Regierung ankündigte, daß sie $60 \%$ der Aktien erwerben werde. Die Bildung eines Arbeiterkommitees, um die Form der Arbeiterkontrolle zu konkretisieren, ist in den Klassenkämpfen von größter Wichtigkẻit.

Selbst wenn die Arbeiterbewegung heute an der Spitze der Massenbewegung steht, die die UP maßgeblich unterstützt, so fand doch auf dem Land der Klassenkampf in den radikalsten Formen statt. Auf dem Lande versuchen Revolutionäre und Konterrevolutionäre die weitgehendsten Aktionen.

\section{Die politischen Tendenzen in der Bauernbewegung}

Die Politisierung der Bauernbewegung ist neu. Sie begann unter dem Einfluß der DC, die unter den bäuerlichen Massen ein Gegengewicht zu der von Sozialisten und Kommunisten beherrschten Arbeiterbewegung zu bilden suchte. Doch die Bauernbewegung ging, sobald sie auf eigenen Füßen stand, über die Grenzen des bürgerlichen Reformismus hinaus. Die ersten Ansätze einer Agrarreform unter der Regierung Frei erschütterte einerseits die Arroganz der Großgrundbesitzer, öffnete andererseits aber die Schleusen für die jahrhundertelang zurückgedrängte Revolte der Bauern. Die Hoffnung, selbst Land zu besitzen und sich aus der Bevormundung der Latifundienbesitzer zu befreien, ließ die Vereinigungen der Bauern und ländlichen Lohnarbeiter rapide ansteigen. 
Anfangs gewann die DC die Unterstützung der Bauernmassen, von der traditionell aufgrund der ökonomischen Abhängigkeit die Großgrundbesitzer profitiert hatten. Aber dann gelang es den Mitgliedern der PS und der PC, die auf dem Land die Erfahrungen der Arbeiterbewegung verbreiteten und die durch die Nähe zu den Bergarbeiterzentren begünstigt waren, zunehmend, Einfluß zu nehmen. Als sich der Prozeß der Landeinnahmen radikalisierte, konnte schließlich auch die äußerste Linke Fuß fassen. Heute ist vor allem die MCR, die revolutionäre Bauernbewegung, die geführt von der MIR unter der Parole „Brot, Erde und Sozialismus“ antritt, verantwortlich für die Besetzungen, besonders für die, die die „mapuches“ machen.

Unter den Bauern waren die „inquilinos“ wegen ihrer Abhängigkeit von den Großgrundbesitzern die wichtigste Basis der reaktionären Partei auf dem Lande. Die Zunahme der „afuerinos“ und ihre gewerkschaftliche Organisierung haben dieser Herrschaft der Reaktionäre die Basis entzogen. Die Latifundienbesitzer setzen gleichwohl ihre politische Hoffnung auf diese Bauern. Um den „mapuches“ zu begegnen, die um den Besitz an Boden kämpfen, hat die Agrarbourgeoisie und die Rechte im allgemeinen Landarbeiter mobilisiert, indem sie diesen erklärten, daß sie mit der Landnahme der „mapuches“ ihre Stellungen verlören.

Dank der Rolle, die die Bauernbewegung heute in den Klassenkämpfen in Chile spielt, sieht die MIR in ihr den explosiven, über Revolution oder Konterrevolution entscheidenden Bereich. In einem kürzlich erschienenen Dokument erklärt die MIR, daß der explosive Charakter der Bauernbewegung „aufgrund ihrer strukturellen Wurzel dahin tendiert, sich gegen die Latifundienbesitzer, gegen die Reichen zu richten". Aber durch die Mechanismen der ideologischen Kontrolle, übe die die Bourgeosei gegenüber den Bauern verfügt, können diese - wie dies schon mehrmals geschah - statt sich gegen ihre wahren Klassenfeinde zu richten, auch gegen falsche Feinde (Fraktionskämpfe, Konflikte mit der Volksregierung) gelenkt werden oder aber aufgefangen werden in kleinbürgerlichen Forderungen. Während DC und FN aus der Bauernbewegung eine explosive Kraft gegen die Regierung machen wollen, will sie die MIR als auslösendes Element für eine sozialistische Revolution benützen.

Aber die innere Dynamik der Bauernbewegung, die die revolutionäre Politik der MIR freigesetzt hat, hat bereits zu Zusammenstößen mit der Regierung geführt. Auf der „nationalen Konferenz der Konföderation der Baciern und Indios" hat Ranquil, Präsident der Föderation der Bauern von Talca und selbst ländlicher Lohnarbeiter, folgende Position bezogen: „Seit einem halben Jahr haben wir eine Regierung unterstützt, die Teil und Produkt unserer eigenen Anstrengungen ist... wir sind einverstanden mit der Produktionssteigerung und haben uns darum bemüht... Jedoch, abgesehen von den "momios", die die Produktion sabotieren, gibt es andere Ursachen für die langsame Produktionssteigerung, für die die Regierung verantwortlich ist und für die wir schließlich verantwortlich würden, wenn wir keine Abhilfe 
schaffen. Es handelt sich um das Bürokratentum". Anschließend gibt er Beispiele von Beamten, die eher den Argumenten der Latifundienbesiłzer Gehör schenken als denen der Arbeiter, er berichtet von Ausflüchten, Rückständen und so weiter. Wenn die gewaltige revolutionäre Energie der ländlichen Lohnarbeiter nicht durch eine mit den Erfordernissen des Aufbaus des Sozialismus gekoppelten revolutionären Politik kanalisiert wird, kann sie ernste Probleme aufwerfen und fatale Folgen für die Revolution haben.

\section{Die Rolle der Randgruppen}

Die ländlichen und städtischen Arbeiter sind das Rückgrat der „Volksbewegung" in Chile. Diesen schließen sich andere soziale Schichten von unterschiedlicher Bedeutung an:

das städtische Lumpenproletariat, im allgemeinen in den „poblaciønes“ konzentriert, dessen großes Problem Arbeitslosigkeit und Wohnungsnot ist; die studentische Jugend, die ideologisch durch den Kampf gegen eine Gesellschaft mobilisiert wird, die ihr die Selbstverwirklichung verweigert;

der neue Mittelstand der Techniker und Spezialisten, die von den Formen der Planung und Verstaatlichung angezogen werden.

Die revolutionäre LinRe hat starke Bastionen im Lumpenproletariat, und es ist ein alltäglicher Anblick, Bilder und Aussprüche von Che, Lenin, Fidel und Mao in der Nähe der „poblaciones“ aufgehängt zu sehen. Die Organisation der „pobladores“ wirft auch zahlreiche Probleme für die Regierung auf. Beispielsweise hat am 14. Dezember ein Führer der Komitees von über $900 \mathrm{Fa}-$ milien das Bestehen einer Miliz unter innen bestätigt, die nach seiner Meinung „der Keim des Sozialismus sei, die zum Schutz der Lager und der Regierung" geschaffen wurde. Aufgrund ihrer Politik gegenüber der Armee konnte die UP diese Miliz nicht akzeptieren. Die Regierung sucht nunmehr nach Wegen, um die extremistischen Kreise der „pobladores“ zu neutralisieren und ihre dringendsten Bedürfnisse zu befriedigen. Die äußerste Linke stellt ihrerseits fest, wie unbeständig diese Schichten sind, die, sobald sie einmal Arbeitsplatz und Wohnung haben, ihre frühere Radikalität abstreifen und sich mit dem Bestehenden abfinden. Dennoch spielen diese Schichten immer noch eine sehr wichtige Rolle, da ihre Probleme nicht so schnell gelöst werden können.

Unter der studentischen Jugend sind die wichtigsten Kräfte die PC, PS, DC, MIR und der MAPU. Doch ist die Zahl der „apolitischen“ Studenten, die das Spiel der Rechten betreiben, immer noch sehr groß. Außerdem gibt es viele Hippies, also Anhänger der "Blumen, Liebe und Droge“. Die Regierung treibt jedoch die Mobilisierung der Studenten voran, indem sie versucht, diese für die Polítisierung der rückständigsten Schichten zu gewinnen.

Der neue Mittelstand ist der bevorzugte Adressat für die DC. Der Sieg, den die Partei bei den Rektoratswahlen der Universität im Juni errang, zeugt davon, daß sie ihren Einfluß nicht verloren.hat. Und selbst in der UP schlägt 
sich der Einfluß dieser Schichten im Technizismus und Bürokratismus nieder.

Deshalb beobachtet die revolutionäre Linke argwöhnisch alle Tendenzen, die zur Bürokratisierung und zu den Konzeptionen eines Staatskapitalismus führen. Letzìlich sind diese Auseinandersetzungen mit dem Kampf zwischen den proletarischen Tendenzen und den Tendenzen der Mitielschichten unter den chilenischen Volkskräfien identisch.

\section{Charakteristik der linken}

War vor den Wahlen die chilenische Linke in zwei Flügel gespalten, von denen der eine auf die Wahlen, der andere auf den bewafineten Kampf setzte, so haben die an erster Stelle Genannten sich in die UP integriert, während die anderen ihre geheimen Vorbereitungen und Aktivitäten in Fichtung auf eine bewaffnete Auseinandersetzung fortgesetzt haben. Nach dem Regierungsantritt Ailendes hat sich die politische Realität als komplexer herausgestellt, als der Oppositionsflügel angenommen hatte. Man sah nämlich, daß sich der revolutionäre bewaffnete Kampf in die reale Bewegung der Klassenkämpfe in Chile einfügen muß. Die gesamte Linke hat versucht, sich den veränderten Bedingungen anzupassen. Die Fähigkeit, aus der Wirklichkeit zu lernen, ist die erste Bewährungsprobe für die Reife jeder Gruppierung der chilenischen Linken.

Auf den ersten Blick brauchten die Organisationen der UP keine Selbstkritik zu üben, da der parlamentarische Weg Früchte getragen hatte. Aber der Erfolg bei den Wahlen enthüllte gerade, daß die Eroberung der Regierung nur eine taktische Waffe auf dem Weg der Eroberung der politischen Gewalt war. Ebenso konnten die „populären“ Regierungsmaßnahmen, die den Interessen des Volkes dienen sollten, nur Übergangsmaßnahmen sein auf dem Weg zum Aufbau des Sozialismus. Der "friedliche Weg“ und die „Volksrevolution“ haben gerade in dem Augenblick auf das deutlichste ihre Unmöglichkeit bewiesen, als sich in den Wahlen eine „Volksregierung“ gebildet haṫ. Deshalb findet die Diskussion über den bewaffneten Kampf und den Aufbau des Sozialismus innerhalb der UP statt.

Es gibt noch keine echt revolutionäre Partei in Chile. Aber es gibt zahlreiche revolutionäre Kräfte, die sich entwickeln und sich im Kampf für den Sozialismus vereinigen können. Wir werden im folgenden versuchen, die einzelnen Kräfte der chilenischen Linken zu charakterisieren.

\section{Die}

Die PC ist eine Partei, die getreu die sowjetische Position in allen internationalen Fragen verteidigt. Sie gibt ihre uneingeschränkte Unterstützung in der tschechischen, polnischen und chinesischen Frage. In der Zeit der OLAS gehörte die chilenische kommunistische Partei zu denjenigen, die die revolutionäre Politik Kubas am heftigsten anprangerten. Die intellektuellen An- 


\section{Proletarier aller Lahder, vereinigt Euch!}

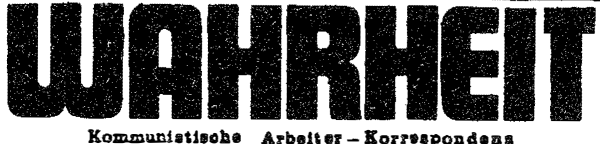

Kommuniatiob Asbelt

Die "Wahrheit" ist eine vom Kommunistischen Bund Bremen herausgegebene politische Zeitung, die sich die Aufgabe gestellt hat, regelmäßig auf alle Fragen des Kampfes der Arbeiterklasse und auf die Kämpfe aller anderen werktätigen Klassen einzugehen und sie vom Standpunkt des wissenschaftlichen Sozialismus zu beleuchten. Sie führt den Kampf gegen die lokale Borniertheit der Zirkel, indem sie versucht, vom Standpunkt der gesamten kommunistischen und Arbeiterbewegung auszugehen und die Auseinandersetzung um die entscheidenden strategischen und taktischen Fragen der westdeutschen Revolution voranzutreiben. Die "Wahrheit" erscheint monatlich.

Aus dem inhalt der letzten Nummern:

Nr. 1 / Februar 1972

- Unsere nächsten Aufgabeh und die Rolle der Zeitung

- Bergarbeiterstreik in England

- Zur Weltwirtschaftskrise

- Organisatorische Fragen der kommunistischen Bewegung in Westdeutschland

Nr. 2 / März 1972

- Nixon in China

- Betriebsrätewahlen 1972

- Die DKP und die Streiks der Metallarbeiter 1971

- Blutsonntag in Irland

Nr. 3 / April 1972

- Maiaufruf des KBB

- Die Ostverträge - eine neue Friedenspolitik ?

- Kapitalistische Schlächterei

- Brandt im Iran

Außerdem in jeder Nummer weitere Artikel und Arbeiterkorrespondenzen mit Berichten aus Betrieben.

Bestellungen sind zu richten an:

Michael Tilgner, 2800 Bremen 15, Postfach 150106. Zahlungen im voraus an das Postscheckkonto Nr. 346264 Postscheckamt Hamburg.

Hiermit bestelle ich die "Wahrheit" ab $\mathrm{Nr}_{\text {. ........ zom }}$ Abonnementspreis von DM 8, - incl. Porto.

Name;

Adresse:

Beruf: 
hänger Kubas waren gezwungen, die „Koexistenz“ Nerudes mit angesehenen amerikanischen Persönlichkeiten in dem Moment öffentlich zu denunzieren, als die Yankees Kuba am schwersten bedrohten, und seine „Koexistenz" mit den Peruanern in dem Moment anzugreifen, wo sie die Guerillas aus De La Puente verjagten. Dennoch wäre es ein großer Irrtum, allein aus diesem Revisionismus in internationalen Fragen Schlußfolgerungen für die PC zu ziehen. Freilich hat das auch wichtige Folgen für die Innenpolitik: Das stalinistische Sektierertum verhindert, daß die Partei ihre starke Basis in der Arbeiterschaft in lebendige Kräfte für die proletarische Revolution verwandelt, die internationalen Thesen des Revisionismus verstellen ihr den Blick für den realen revolutionären Prozeß. Aber innerhalb dieser Grenzen hat die PC ihre Aufgabe erfüllt, eine kämpferische Kraft aufzubauen und den arbeitenden Massen eine politische Alternative anzubieten. Die Kommunistische Partei Chiles hat alles erreicht, was mit einer reformistischen Politik innerhalb der demokratisch-bürgerlichen. Legalität zu erreichen ist. Was ihr allerdings fehlt, ist eine revolutionäre Politik, um die Arbeiterklasse im Hinblick auf die Machtübernahme auszubilden. Nur in einem ökonomischen Angriffskampf und in einem Wahlkampf hat die PC (und die PS) dieses sozialistische, antikapitalistische, legalistische und reformistische Proletariat gebildet.

Der Wahlsieg hat noch den alten Absolutheitsanspruch der PC und ihre sektiererische Haltung gegenüber dem „ultralinken Abenteuertum“ verstärkt. Während die anderen Organisationen der UP eine offenere Politik gegenüber der äußersten Linken verfolgen, hat die PC alles ihr mögliche getan um die Zusammenarbeit zwischen der UP und der äußersten Linken abzubrechen. In den Wahlen für die „Föderation der Studenten Chiles“ (FECH) hat diePC jedes Bündnis mit der von der MIR geleiteten revolutionären Front abgelehnt, obwohl jedermann wußte, daß dadurch die von der Rechten unterstützte DC gewinnen würde. Dieses verhängnisvolle Ergebnis wurde einzig und allein dadurch verhindert, daß die MIR ihre Liste zurückzog, die der UP unterstützte und das Sektierertum der PC kritisierte. Diese Politik setzte die PC in Conception fort, wo einige Mitglieder der PC einen Anhänger der MIR töteten und einen anderen verletzten. Die politische Scharfsicht der MIR, die das brutale Sektierertum angriff, gleichzeitig jedoch die PC zur Bildung einer Einheitsfront gegen die wahren Klassenfeinde aufrief (die Rechte kündigte schon den „Kampf zwischen MIR und PC“ an), die persönliche Intervention Allendes und die leidenschaftlichen Folgen dieser Affäre haben bis in die PC hinein Auswirkungen gezeigt. Andererseits hat die MIR jedoch an der Basis Abkommen mit Mitgliedern der PC schließen können, um den Kampf unter den Bauern zu führen. Schließlich haben Abmachungen zwischen den Führungsspitzen die allmählichen Wandlungen der PC bezeichnet. Obwohl es noch keinen organisierten Protest innerhalb der kommunistischen Partei gibt, muß man doch zwei Faktoren in Rechnung stellen: 1. Es gibt einen deutlichen Unterschied zwischen dem Verhalten der Funktionäre, die mit der Verwaltung verbunden sind und den Staatsapparat erhalten wollen, und den PC-Genossen, die näher an den Massen und für deren Stärkung arbeiten. Während die sek- 
tiererischen Tendenzen aus den Funktionären die wichtigsten Agenten der Bürokratisierung machen werden, müßten die zweiten wegen ihrer kommunistischen und kämpferischen Einstellung zu revolutionären und proletarischen Lösungen treiben.

2. Ohne daß sie ihre theoretischen Prinzipien neu formulieren, bereiten sich gewisse Teile der PC auf die Möglichkeit eines bewaffneten Konflikts und den Aufbau des Sozialismus vor. Sie wissen, daß, selbst gegen ihren erklärten Willen, die Reaktion sie immer noch als Todfeinde ansieht.

Die Sozialistische Partei (PS) ist keine Partei im leninistischen Sinne. In ihrer lockeren Organisatiosstruktur ähnelt sie sozialdemokratischen, föderalistischen und liberalen Organisationen. Gleichwohl haben sich Teile der Partei unter dem Einfluß der kubanischen Revolution radikalisiert. Als die PC die neue von den Kubanern unterstützte revolutionäre Linke angriff, hat die PS offen die OLAS verteidigt. Allerdings nahm die Radikalisierung verschiedene Formen an: eine aggressive Sprache in den Wahlkämpfen für die einen, für die anderen die Vorbereitung der ländlichen Guerilla; für die dritten schließlich die Bildung revolutionärer Stützpunkte unter den sozialistischen Arbeitermassen. Obwohl die Basis der PS „linker" ist als die der PC, ist ihre interne Differenzierung größer und die Wirksamkeit zentraler Anordnungen geringer. Jedoch hat die von der neuen Basis hervorgerufene Dynamik allgemeine Wandlungen in der Partei hervorgerufen. Auf dem letzten, im Januar 1971 abgehaltenen Kongreß hat der linke Flügel, den die Mehrheit dẹr Jugend unterstützte und der sich der Notwendigkeit eines revolutionären Übergangs zum Sozialismus bewußt war, den Sieg über den rechten Flügel davongetragen, den besonders traditionelle Politiker der Partei unterstützen. Der neue Generalsekretär erklärte: „Wenn es keinen gewaltsamen Zusammenstoß gibt, sind wir verraten worden." In einem Interview, das er der Zeitschrift „Punto Final“ im Dezember gab, hat Altamirando auf die Frage, ob sich die UP auf einen bewaffneten Konflikt vorbereite, geantwortet: „Ja, wir bereiten uns darauf vor. Und wir glauben, daß die Entwicklung der Radikalisierung des Prozesses uns dahin führen müssen. Es wäre sicher besser, wenn ich mich täuschte. Aber ich glaube leider, daß Chile keine Ausnahme in den revolutionären Prozessen sein wird, die in der Weltgeschichte stattgefunden haben." Und neulich hat die Agrarkommission der Partei Stellung bezogen: „Wir müssen mehr auf den politischen Inhalt der Maßnahmen als auf Produktions- und Produktivitätserhöhungen achten."

Die MAPU stützt sich ihrerseits auf zahlreiche alte Bastionen der DC, die sie bei der ländlichen Gewerkschaftsarbeit und bei der Mobilisierung der Studenten sowie Teilen der städtischen Arbeiter gewann. Der Bruch mit der DC ist Folge einer Radikalisierung der Basis, die noch nicht abgeschlossen ist. Die neue Organisation akzeptiert nicht mehr die Augenwischerei eines „dritten Weges:" und versucht, wenngleich nur empirisch, sich in die Klassenkämpfe einzuordnen. Die noch bestehende programmatische Unbestimmtheit entspricht der bunten Vielfalt der Mitglieder der Partei. Wir finden in ihr sowohl 
Techniker und Politiker die sich auf der Linken der DC" ansiedeln und die Politik im alten Stil fortsetzen wollen, als auch Genossen, die durch die Mobilisierung der Massen herangebildet wurden.

\section{Die MIR}

Außerhalb der UP ist die wichtigste Organisation der Linken die MIR. Erst am Vorabend der Wahlen hat die MIR deren Bedeutung begriffen. Diese politische Vespätung war die Folge der politisch-militärischen Ausrichtung der Gruppe. Die MIR hat von der Radikalisierung der Jugend und den revolutionären Neigungen unter pobladores und Bauernschaft profitiert. Aber ihre Tendenz zum Guerillakampf hat wirksame Eingriffe in die Klassenkämpfe erschwert. Da sie mit dem Ziel gegründet wurde, den bewaffneten Kampf auf dem Land zu entzünden, hat die MIR nicht die Reichweite der von den Arbeitern geführten Kämpfe gesehen..

Jedoch einige Monate vor den Wahlen hat die MIR eingesehen, daß sie kein Interesse daran haben kann, sich gegen die Kampagne der UP zu stellen. Die MIR hat die Ungereimtheiten der UP kritisiert und gleichzeitig versucht, die Wahlkampagne revolutionär zu ergänzen und auszurichten. Den Wahlsieg hielt die Gruppe zwar für einen großen Sieg der Arbeiter, aber sie hat stets auf die Grenzen der Politik der UP hingewiesen. Die Schwäche der UP liege, so führte die MIR aus, in ihrer ",heterogenen politischen Zusammensetzung" und im Fehlen einer „eigenen militärischen Macht" begründet. Daraus folgt die Taktik der MIR, die auf das Aufzeigen der Grenzen einer Volksregierung innerhalb eines bürgerlichen Staates und der Notwendigkeit einer Klassenauseinandersetzung hinausläuft, zugleich aber auch die effektive Vorbereitung dieses Konfliktes beinhaltet.

Die Taktik der MIR besteht mithin darin, daß sie die Regierung kritisch unterstützt. Sie unterstützt sie im Kampf gegen die Rechte und bei revolutionären Maßnahmen. Ebenso wie sie Genossen als persönliche Schutztruppe für Allende bereitgestellt hat und Hinweise gegeben hat, die mehrere rechte Verschwörer ins Gefängnis brachten, hat sich bei Konflikten zwischen der Rechten und der Linken die MIR stets mit der UP verbündet. Außerdem hat sie die Aufstellung einer bewaffneten Macht für die Klassenkonflikte vorangetrieben und die Einheit mit dem proletarischen Flügel der UP gesucht, um eine Klassenfront auszubilden. Auch in den Massen versuchen die Anhänger der MIR, den revolutionären Prozeß zu radikalisieren. Auf dem Land zielt ihre Aktion auf eine Mobilisierung der Arbeiter und der armen Bauern ab, indem sie außerhalb der Legalität Land besetzen und versuchen, bäuerliche Selbstverwaltungsorgane zu schaffen. Auch in den Städten gehören Fabrikbesetzungen mit der Bildung lokaler Streikkomitees zu den Aufgaben der MIR. Dabei versucht die Gruppe von ihren Erfahrungen in den Kämpfen der pobladores zu profitieren. Diese von der MIR unterstützte Dynamik führte jedoch zu Zusammenstößen mit der Regierung. Im Mai, als die Regierung repressive Maßnahmen gegen die Bauern ergriffen hatte, die Ländereien besetzt hatten, 
hat die MIR diese Regierungspraktiken öffentlich angegriffen und erklärte, daß „die verschwörerische Arbeit der Herrschenden und der Reichen selbst unter Regierungsbeamten und Anhängern der UP Erfolg gehabt habe." Obwohl die MIR ihre Divergenzen mit der UP „in politischen Diskussionen über den richtigen Weg im Kampf gegen den Klassenfeind" lösen wolle, distanziere sie sich von der Regierung, wenn diese Gewalt gegen Arbeiter und Bauern anwende. Nachdem die MIR „noch einmal ihr tiefes Vertrauen in den revolutionären Willen der Arbeiter- und Bauernmassen“ bestätigt hat, „,denen die Regierung der UP große Möglichkeiten der Initiative und Mobilisierung gegen ihre Klassenfeinde geboten hat", erklärte sie es als ihre Pflicht, „die gerechten Forderungen der Armen des Landes und der Städte zu verteidigen, die allein über genug Kraft verfügen, um endgültig die Bourgeoisie und den Imperialismus zu besiegen und alle Macht für die arbeitende Klasse zu erobern."

Der Aufruf endet damit, daß zur Verurteilung aller repressiven Maßnahmen, zum Kampf gegen eine Aufstellung „mobiler Polizeitruppen“, zur Befreiung aller festgenommenen Bauern und zur Enteignung aller verlassenen Bauernhöfe aufgerufen wird. Jedesmal, wenn Konflikte zwischen der MIR und der UP bestehen, versuchen die bürokratischen Teile der Regierung die Brücke zur revolutionären Linken abzubrechen. Aber bislang haben die revolutionären Teile der Regierung, die Geschicklichkeit Allendes und der MIR diesen Bruch verhindert. Die MIR bleibt durch ihre richtige Taktik ein Pol im politischen Leben, den alle Gruppen anerkennen müssen. Übrigens begünstigt es die Gruppe, daß sie den revolutionären Prozeß Chiles in seiner Totalität begreift und deshalb sozialistische Transformationen als unausweichlich für den Sieg gerade gegen die Rechte ansieht.

Wir können jedoch noch nicht sagen, ob die MIR schon den Erfordernissen einer proletarischen Revolution entspricht, die sie verteidigt. Einerseits fehlen ihr noch sichere Stützpunkte in der Arbeiterklasse. Ihre Organisationsform hat diese Verankerung verzögert. Freilich versucht die MIR bei Fabrikbesetzungen die Bildung von Basisgruppen des Proletariats voranzutreiben, aber ihr übertriebenes Verschwörergehabe erschwert eine echte Verankerung in der Arbeiterklasse. Andererseits ist es der MIR noch nicht gelungen, durch Stellungnahmen zu allen Ereignissen im nationalen politischen Leben präsent zu sein. Ein,gutes Indiz hierfür ist das Fehlen einer nationalen Zeitung der Gruppe. Es gibt noch viele andere, viel kleinere Gruppierungen in der revolutiǫnären Linken, die sich außerhalb der UP gebildet haben. Im allgemeinen handeln sie ähnlich wie die MIR. Jedoch trennen sie sich in ihrer Einschätzung von der Regierung Allende. Einige haben sich der UP angeschlossen, andere von dieser entfernt und global den Regierungsblock kritisiert.

Die maoistische PCR leistet eine gewisse Organisationsarbeit in den Massen, und ihre Presse wird unter Studenten gelesen. Aber ihre Fehleinschätzung der Wahlen und der Regierung trennen die Gruppen von den wichtigsten revolutionären Kräften Chiles. Die Richtung „Octobre“, eine trotzkistische 
Abspaltung von der MIR (es gibt noch andere kleine trotzkistische Gruppen, einschließlich solcher in der PS) hat in der Vergangenheit die Neigung der MIR zum bewaffneten Kampf kritisiert und kritisiert heute Kompromisse, die die MIR mit der UP schließt. Denn diese Gruppe will die Regierung direkt bekämpfen und lehnt alle Kompromisse mit der UP ab. Die Gruppe ist jedoch sehr klein.

Die MR 2 (movimiento revolutionario Manuel Rodrigues, nach einem von der Reaktion getöteten Bauernführer benannt) war früher eine Organisation, die noch mehr als die MIR auf den bewaffneten Aufstand hin orientiert war, aber sie versucht heute, innerhalb der UP zu arbeiten. Sie verteidigt den sozialistischen Charakter der Revolution und versucht, die proletarischen Teile der UP zu verstärken. Sie bleibt aber zahlenmäßig nach schwach. Die Bewegung "Ranquil" versucht auch, die proletarischen Teile der UP zu verstärken, indem sie dieser beitritt. Ihre "Selbstkritik" und die Abwendung von ihrem früheren Antiparlamentarismus haben auch dazu geführt, daß sie ihre Empfehlung widerrief, daß ihre Mitglieder der PC oder PS beitreten sollten. Es ist unmöglich, den genauen Zustand der sich beständig wandelnden Organisationen zu beschreiben. Dennoch glauben wir, daß trotz ihrer Irrtümer der Einfluß der MIR entscheidend bleibt. Wir zweifeln nicht, daß die proletarische Avantgarde in Chile sich herausbilden wird unter Teilnahme von Revolutionären, die in der PS sind, anderen, die in der PC sind und dort einen Kampf in der Partei führen müssen, anderen Gruppen, die kleiner sind und entweder aus der MR 2, PCR oder der MAPU kommen. Durch ihre aktuelle Stärke und ihre Stellung zu anderen politischen Kräften bleibt die MIR heute der wichtigste revolutionäre Faktor. Ihre Entwicklung, ihre Fähigkeit, sich mit breiten Teilen des Proletariats zu verbinden und eine globale revolutionäre Strategie auszubilden, ist eine grundsätzliche Gegebenheit für die Zukunft der Revolution in Chile.

\section{Schlußfolgerungen}

Entscheidend bleibt die .Frage nach dem Aktionsprogramm, das die revolutionären Kräfte für Aufgaben vereinigen kann, die den wirklichen Übergang zur sozialistischen Macht in Chile realisieren.

Die Regierung Allende kann nur eine Übergangsregierung sein. Mit ihrer sozialen Basis und mit den ihr zukommenden Aufgaben kann sie nur die Türen zum Sozialismus öffnen. Um ihre Basis zu stärken, um die drohende Konterrevolution zu besiegen, muß sie die ökonomischen und politischen Maßnahmen vorantreiben, die zum Sozialismus führen. Eine Regierung, die sich auf die politische Kraft der Arbeiter stützt, aber gleichzeitig in die ökonomische und politische Struktur des Kapitalismus eingegliedert ist, hat nur zwei Alternativen. Entweder wählt sie den sozialistischen Weg und zerstört die politische und ökonomische Macht der Bourgeoisie, oder sie zögert, be- 
schwichtigt und läßt die bürgerlichen Institutionen unangetastet. Das aber wäre der kapitalistische Weg. Wenn die bürgerlichen Institutionen bestehen bleiben, wenn die Wirtschaft nach kapitalistischen Gesetzen ausgerichtet bleibt, wenn die Macht in den Händen der Bourgeoisie verbleibt, wird diese über kurz oder lang den Sturz der Volksregierung erreichen und die sie bedrohenden Massenorganisationen zerstören.

Die Regierung der UP nimmt keine entschlossene Haltung ein, um diesen Übergang zum Sozialismus einzuleiten. Vielmehr schwankt sie zwischen den Bedingungen eines revolutionären Übergangs und Kompromissen mit den bürgerlichen Institutionen, zwischen den proletarischen Revolutionären und kleinbürgerlichen Bürokraten. Ein Vergleich der Regierung Allende mit den „Volksfrontregierungen" der 30er Jahre scheint uns übertrieben, denn die Bourgeoisie fehlt in der Regierung der UP. Trotz des Reformismus und der Kompromisse mit dem Kleinbürgertum, das der Regierung angehört, bleiben die Arbeiter die wichtigste Kraft. Deshalb bleibt die Taktik der MIR, die Regierung kritisch zu unterstützen, richtig. Aber diese Einstellung zur Regierung kann nicht statisch sein, denn man muß die die Regierung unterstützenden Kräfte vorwärts zum Sozialismus treiben. In dieser Hinsicht erhält das Übergangsprogramm seine ganze Bedeutung.

\section{Folgende wichtige Probleme muß die chilenische Linke noch lösen:}

1. Die großen ökonomischen Veränderungen. Das wichtigste Problem ist mit den notwendigen Verstaatlichungen verbunden, die den Übergang zu einer sozialistischen Wirtschaft erlauben sollen. In einer Analyse hat die MIR aufgezeigt, daß die Regierungsmaßnahmen, die den Konsum ausweiten, auch den Anreiz für die Schlüsselsektoren des Kapitalismus hemmen. Wenn die Wirtschaft weiterhin von diesen Sektoren abhängig bleibt, kann es $1972 \mathrm{zu}$ einer großen Wirtschaftskrise kommen. Schon heute muß die Frage der Enteignungen gestellt werden, damit man das Rad nicht rückwärts drehen muß. Diese Maßnahmen sind nicht rein administrativen Charakters. Sie wären gebündelt und ohne Entschädigung durchgeführt - ein Todesstoß für die chilenische Bourgeoisie. Deshalb muß man genau den Termin wählen, die Massen vorbereiten und innen die Notwendigkeit der Maßnahmen enthüllen. Auch auf dem Land erfordern die großen Verwandlungen eine Mobilisierung der ländlichen Massen. Manche Leute denken, daß die Enteignungen wegen der Schwäche der Latifundienbesitzer auch von oben gemacht werden könnten. Aber der politische Wert dieser Maßnahme besteht gerade darin, daß er der Revolution eine soziale Basis schafft. Es kann nicht darum gehen, den Bauern durch Land zu beruhigen, sondern inn anzuregen, daß Land zu erobern, um die Mobilisierung der Bauern und ihre Einheit mit dem Proletariat im Kampf gegen die bürgerliche Macht zu vergrößern.

2. Bewaffneter Kampf und revolutionäre Armee. In naher Zukunft kann sich diese Frage mit besonderer Schärfe stellen. Um für eine Entscheidungsschlacht gewappnet zu sein und nicht von zögernden Alliierten abhängig zu 
sein, muß die Linke ihre eigene Macht aufbauen. Dabei ist die Taktik sicher richtig, Teile der Offiziere zu neutralisieren oder zu gewinnen, aber von diesen darf man nicht abhängig sein. Die politische Arbeit, die Masse der Soldaten zu umwerben, muß durch die Aufstellung von Arbeiter- und Bauernmilizen vervollständigt werden. Augenblicklich darf man sicher nicht voreilig handeln, legaler Schutz ist wichtig, aber man muß sich vorbereiten. Man darf nicht wie die UP sowohl auf die Ausbildung von Volksmilizen verzichten als auch in den Massen gefährliche Illusionen über die Armee nähren.

3. Die Doppelherrschaft. Man muß Organe der städtischen und ländlichen Arbeiter, der Bauern, Studenten und Soldaten bilden, die die lokalen Kämpfe leiten und sich nach und nach als Basis der revolutionären Herrschaft behaupten. Deshalb müssen sie repräsentativ für ihre Basis sein, die materiellen Mittel zur Durchsetzung politischer Entscheidungen haben, mit der Ausdehnung des revolutionären Prozesses verbunden sein und eine eigene Miliz haben. Die „Volkeinheitskomitees" haben ihre Rolle ausgespielt, da sie nur für die Wahlen gebildet wurden. Die neuen Organe müssen jetzt für die revolutionäre Umwälzung der Gesellschaft eine Basis schaffen, die Macht der Bourgeoisie und ihrer Agenten zerstören. Die Bauernkomitees zur Besetzung des Landes und die Arbeiterkomitees zur Kontrolle der Betriebe können die Keimzelle der Doppelherrschaft sein.

\section{Die Eroberung der Mittelschichten.}

Um das gegenwärtige Gleichgewicht zugunsten der Linken zu zerbrechen, ist es wichtig, daß die armen christ-demokratischen Arbeiter und Bauern politisch gewonnen und die Mittelschichten (der Armee, der Verwaltung, der kleinen Kaufleute und Handwerker u. a. m.) neutralisiert werden. Wichtig ist jedoch die Erkenntnis, daß die christ-demokratischen Arbeiter erst dann ins Lager der Revolution überwechseln, wenn die Revolutionäre ihr Vertrauen in die sozialistische Revolution zeigen. Am konkreten Beispiel muß man geduldig die Verschleierungstaktik der Christ-Demokraten aufzeigen, um nicht den Kontakt zu den christ-demokratischen Arbeitern abzubrechen und gemeinsame Formen des antikapitalistischen Kampfes mit ihnen zu finden. Aber man darf nicht die revolutionären Initiativen „kastrieren“, nur um die Mittelschichten nicht zu erschrecken. Gewiß sind diese Probleme nicht leicht zu lösen, aber entscheidend ist es, die revolutionären Initiativen der Massen zu unterstützen und die reformistischen und legalistischen Teile der Bevölkerung auszuschalten.

Die Verbindung von legalen und illegalen Kampfformen in Chile hat Unsicherheit über die wirklichen Probleme verbreitet. Die Überschätzung der legalen Mittel innerhalb der UP hat verhindert, daß bislang eine wahre revolutionäre Strategie ausgearbeitet wurde. An deren Stelle trat die Handwerkelei, die von den schwankenden Verbündeten und den bestehenden Institutionen bestimmt wurde. Die Tendenz in der revolutionären Linken außerhalb der UP, 
nicht die Bedeutung der legalen Taktik zu erkennen, hindern diese auch, eine revolutionäre Strategie auszubilden.

Die Ausarbeitung eines Übergangsprogramms durch die revolutionäre Linke muß taktischen Tätigkeiten vorangehen. Man kann einige Aspekte nicht öffentlich erklären. (So muß man auf offizielle Stellungnahmen über die Zerstörung oder Ersetzung der offiziellen Armee verzichten, während man Milizen organisiert.)

Die bedingungslose Unterstützung der gegenwärtigen Politik der UP ist ebenso unsinnig wie der Bruch mit ihr. Es geht vielmehr darum, die Maßnahmen zu bestimmen, die zu einem revolutionären Bruch führen und den gemeinsamen Kampf für diese Maßnahmen zu organisieren. Dieser Kampf wird neue revolutionäre Kräfte wecken und den Arbeitern neue Macht erobern, ebenso wie er eine revolutionäre Avantgarde hervorbringen wird, die fähig ist, die Revolution bis zum Ende durchzuführen. 